\title{
Effect of Oral Administration of Megasphaera elsdenii on Performance of Holstein Cows During Early Lactation
}

\section{THESIS}

Presented in Partial Fulfillment of the Requirements for the Degree Master of Science in the Graduate School of The Ohio State University

\author{
By \\ Katilyn D. Stevens, B.S. \\ Graduate Program in Animal Sciences
}

The Ohio State University

2013

Thesis Committee:

Maurice L. Eastridge, Advisor

Jeffrey L. Firkins

Kristy M. Daniels 


\section{Copyrighted by}

Katilyn D. Stevens

2013 


\begin{abstract}
Transition cows have a high risk for metabolic disease within the first 30 days in milk (DIM). Administration of direct-fed microbials (DFM) may reduce the adverse impacts that fresh cows experience during this transition period. Megasphaera elsdenii is a lactic acid-utilizing bacterium that has shown promise as a potential DFM during the transition period. Primi- and multiparous Holstein cows $(n=162)$ at a commercial dairy herd were assigned to 1 of 4 treatments: 1) control (no dose) (n=44), 2) $200 \mathrm{~mL}$ Lactipro $(M$. elsdenii, $1 \times 10^{8} \mathrm{cfu} / \mathrm{mL}$; MSBiotec, Littleton, CO) when cows entered ( -14 DIM) the close-up pen (n=45), 3) 200 mL Lactipro at 1-3 d postpartum (n=39), and 4) $200 \mathrm{~mL}$ Lactipro prepartum and $200 \mathrm{~mL}$ at 1-3 d postpartum $(\mathrm{n}=34)$. Close-up cows were fed $72 \%$ forage (63:37 corn silage and wheat straw), and upon calving, cows entered the high group and were fed 40\% forage (90:10 corn silage:wheat straw). The BCS was similar among treatments and no treatment by time interaction occurred. There was no difference in milk yield among treatments $(39.7,39.7,39.5$, and $39.8 \pm 0.97 \mathrm{~kg} / \mathrm{d})$ or peak milk yield. Treatment by parity interactions were detected $(P<0.05)$ for milk yield and peak milk yield in which mature cows ( $\geq 3$ lactations) dosed prepartum had higher daily milk yield and peak milk than the control and pre- and postpartum dosed cows but did not differ from the postpartum dosed cows. The test-day milk fat and protein percentages were similar among treatments. Test-day milk fat was higher $(P<0.01)$ for the first $(3.88 \%)$ versus second (3.38\%) test-day but it was within expected levels, which is
\end{abstract}


reflective of the low incidence of ketosis in the study. There was a treatment by parity interaction $(P<0.01)$ for milk protein. Milk protein percentage was higher for $2^{\text {nd }}$ lactation cows dosed prepartum than control or cows dosed pre- and postpartum but did not differ from cows dosed postpartum. Control and pre- and postpartum dosed cows with $\geq 3$ lactations had higher milk protein percentages than those dosed only prepartum but were not different from cows dosed only postpartum. The SCC did not differ $(P>$ $0.10)$ by treatment or DHI test-day and averaged $333\left(\times 10^{3}\right)$ cells $/ \mathrm{ml}$ across all treatments. Based on urine ketones, only $2.5 \%$ of the cows in the study experienced clinical ketosis, but cows with $\geq 15 \mathrm{mg} / \mathrm{dL}$ urine ketones were 8.33, 14.3, 14.3, and 0\% for treatments, respectively. Health incidences were low in this study and did not differ among the treatments. Reproductive performance also did not differ among the treatments. Based on this study, dosing with M. elsdenii prepartum may improve ruminal conditions of high-producing (higher parity) transition cows whereby milk yield is increased. Concentrations of dietary starch and NDF fed both prepartum and postpartum may affect animal response to dosing with $M$. elsdenii. 


\section{Dedication}

Dedicated to my parents, Tony and Marilyn Stevens, and my brother, Christopher Stevens, for always supporting me in all endeavors I undertake and for constantly showing an interest in my life. 


\section{Acknowledgements}

Dr. Maurice Eastridge, it seems only fitting that your name appear first in this section as you are the main reason I decided to earn a graduate degree in my year off before veterinary school. You have been my mentor for the past two years and I am grateful to have had the opportunity to work with you on so many research projects. You have not only been my advisor, you have been the one person I know I can always seek guidance from and will challenge me. Second, I would like to thank both Dr. Kristy Daniels and Dr. Jeff Firkins for willingly agreeing to serve on my committee and for always having helpful suggestions when I needed them.

To the interns and fellow graduate students whom have all helped me with this project in some form, I cannot express my gratitude to you enough. Shirron LeShure, you made the early morning trips down to the dairy on sampling days absolutely unforgettable, and I could not imagine trying to get all the milk samples by myself and make it to seminar on time. Sarah Finney, thank you for spending your Tuesday mornings with me collecting blood and urine samples before having to rush off to your afternoon classes, sometimes still smelling like cow. Danni Ye, thanks for helping me figure out the blood assay kits and for always answering my questions. To Jessica Pempek and Benjamin Wenner, you two have probably been two of my best friends this past year and I am so glad I had the opportunity to work alongside you, even though you make fun of me often. To Josie Plank, I cannot thank you enough for your instruction in the lab and 
all of the advice you have given me both scientific and personal; you are a truly wonderful person. Thank you to Jill Stiverson, even though I do not work in your lab; you assisted me in using your equipment and were always very helpful with any requests I had. To everyone I have not mentioned, you have all made your mark in my life and I am glad to have to gotten to know you this past year.

I would like to thank MSBiotech ${ }^{\circledR}$ for their funding of this project and for providing us with the Lactipro product. To the Miedema Family, especially Andy Miedema, this project would not have been possible without your willingness to let me do this project at your dairy farm. Thank you for allowing me access to your production records and for providing me with any data I requested. I would also like to thank the herd manager, Tony, for being patient with me in the chaos at the beginning of the project and for dosing the cows after calving and for helping me get stubborn cows into headlocks.

Last, but certainly not least, I would like to thank all of my lovely black and white ladies of the Miedema Dairy. It was amazing how quickly I fell in love with each of you and memorized all of your different personalities. But not for the dairy cows, none of this would have been possible. Thank you mamas! 


\title{
Vita
}

June $2009 \ldots \ldots \ldots \ldots \ldots \ldots \ldots \ldots$
Springfield, Ohio

\section{Fields of Study}

\author{
Major Field: Animal Sciences \\ Specialization: Dairy Cattle Nutrition
}




\section{Table of Contents}

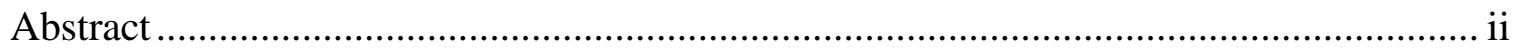

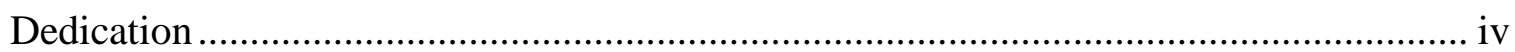

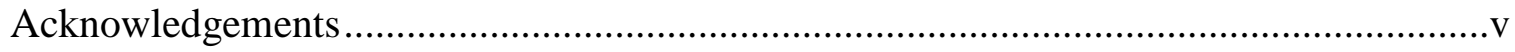

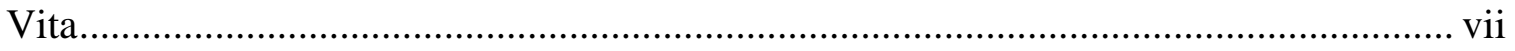

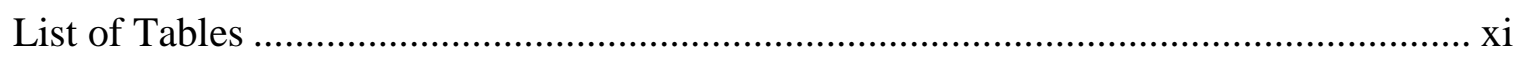

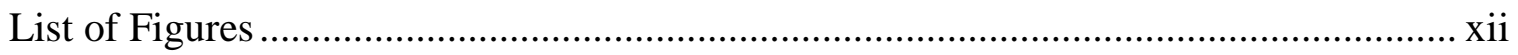

CHAPTER 1: INTRODUCTION ...................................................................... 1

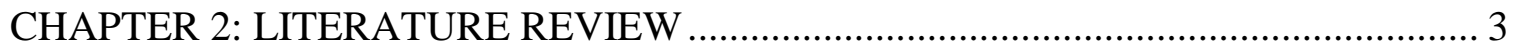

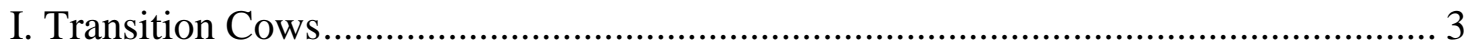

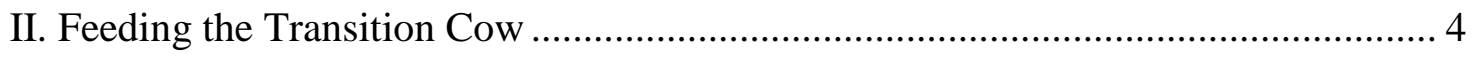

A. Rumen Microbial Population ..................................................................... 4

Effect of Changing to a High-Grain Diet......................................................... 5

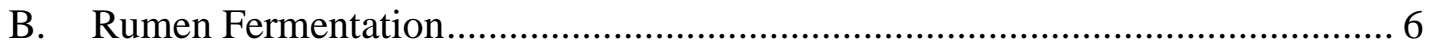

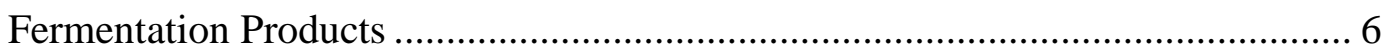

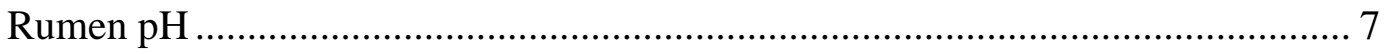

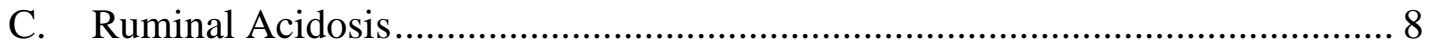

Rumen Microorganism Changes Associated with Acidosis ............................... 9

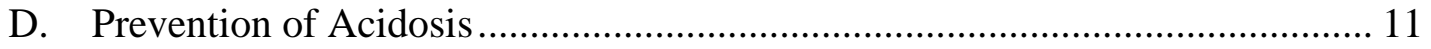




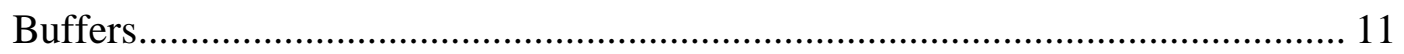

Feeding Management............................................................................... 12

Environmental Stress (Heat Stress and Grouping) ......................................... 14

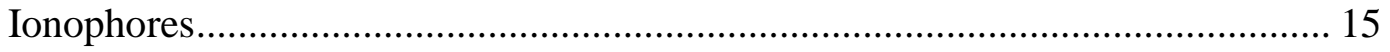

Direct-Fed Microbials ....................................................................... 17

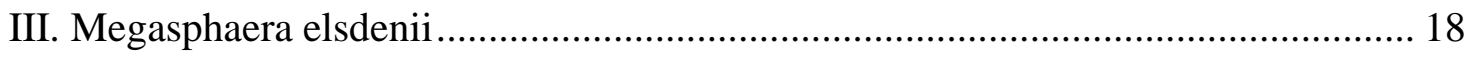

A. Metabolism of Lactate by M. elsdenii ....................................................... 19

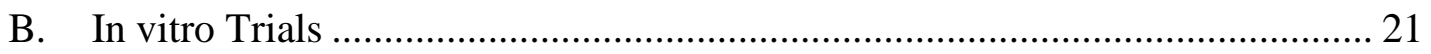

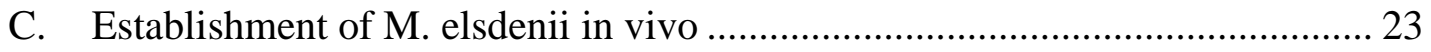

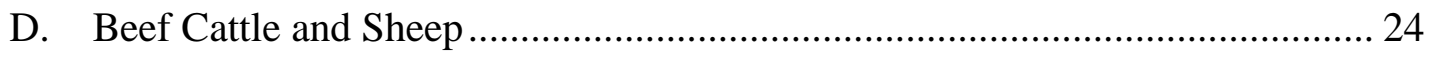

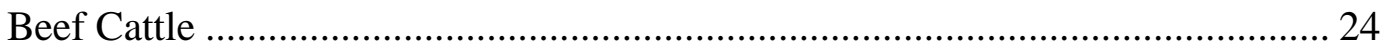

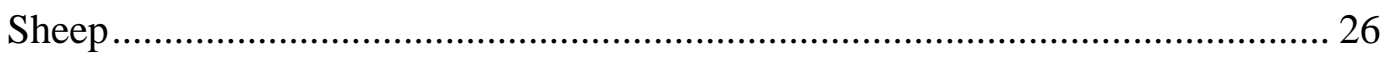

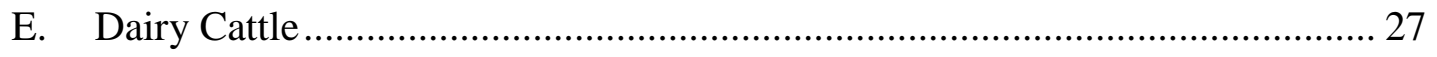

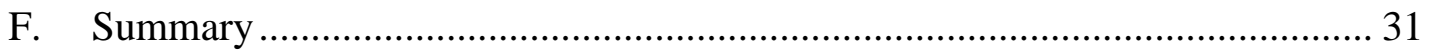

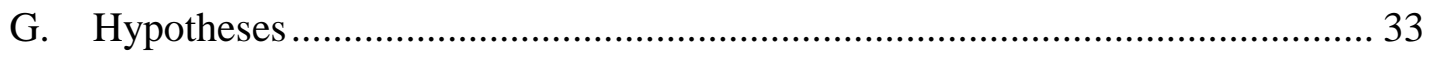

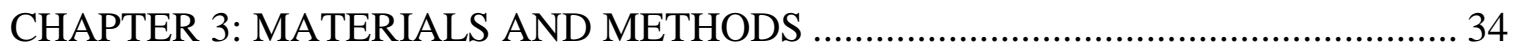

Experimental Design, Treatments, and Diets ..................................................... 34

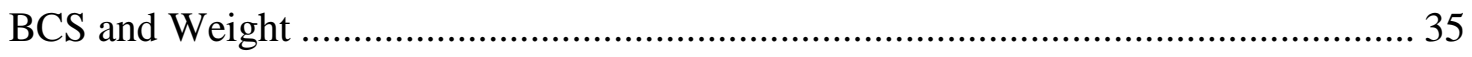

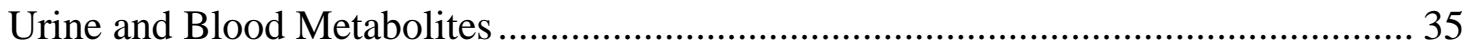

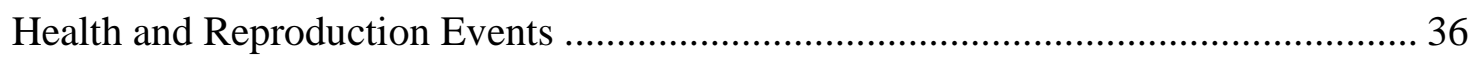

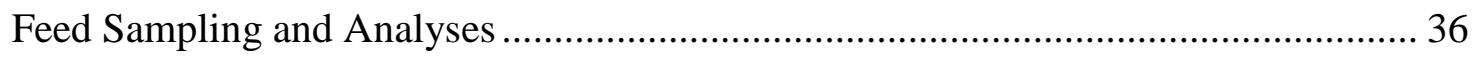

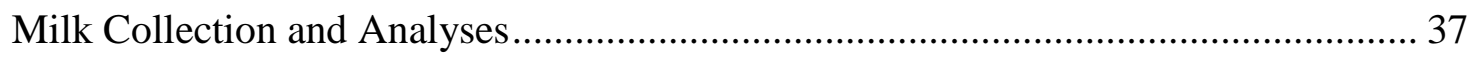


Statistical Analysis

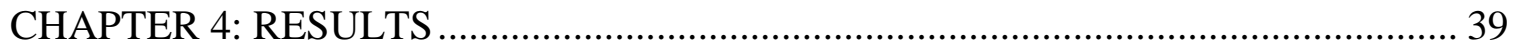

Experimental Design, Animals, and Treatments ................................................... 39

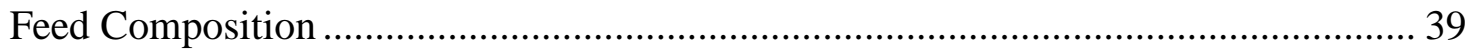

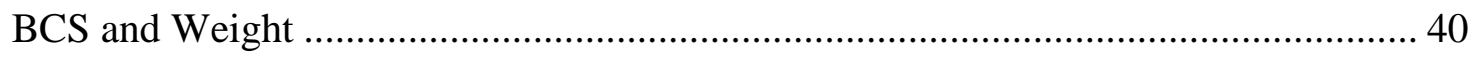

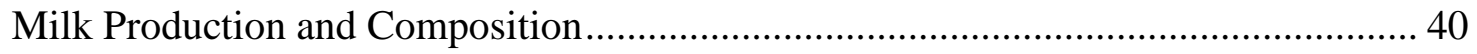

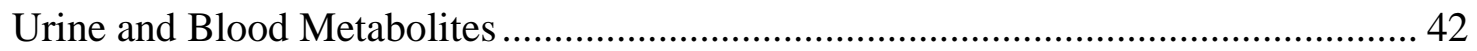

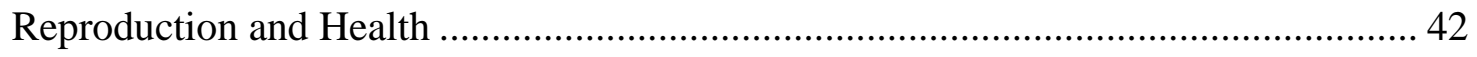

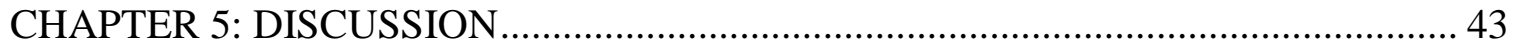

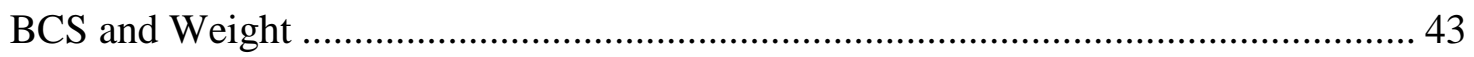

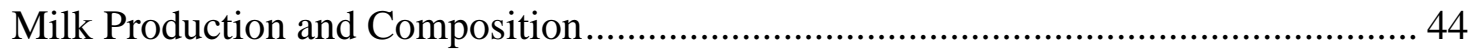

Urine and Blood Metabolites ............................................................................ 46

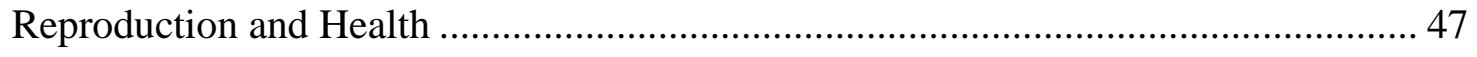

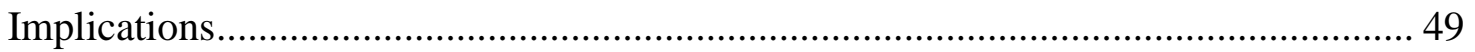

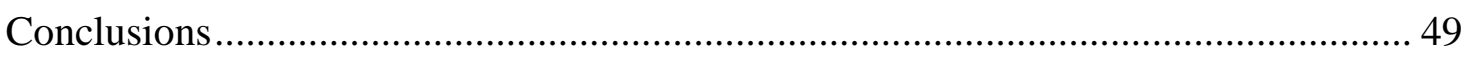

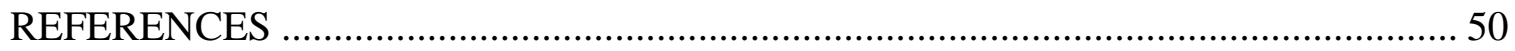

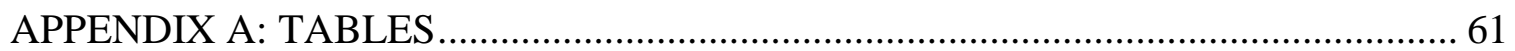

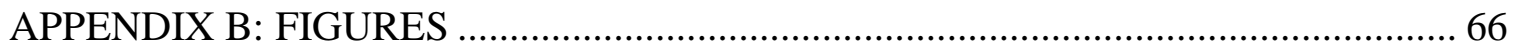




\section{List of Tables}

Table 1. Ingredient composition of dry cow and lactating (high) cow diets (\% of DM).. 62

Table 2. Chemical composition of the diet formulated by the herd nutritionist and the chemical composition of the actual diet fed

Table 3. Least square means of body condition score, body weight, urine ketones, plasma NEFA and BHBA, milk production, and milk composition in cows not dosed and cows dosed with M. elsdenii $\sim 14 \mathrm{~d}$ prepartum, 1-3 d postpartum, or $\sim 14 \mathrm{~d}$ prepartum and ..... 64

Table 4. Incidence of health events within each treatment (\% of cows with health event) until 90 DIM and least square means for reproductive performance until 150 DIM for cows not dosed and cows dosed with M. elsdenii $\sim 14 \mathrm{~d}$ prepartum, 1-3 d postpartum, or $\sim 14 \mathrm{~d}$ prepartum and 1-3 d postpartum. 65 


\section{List of Figures}

Figure 1. Body condition score from 2 wk prepartum to 90 DIM for control, prepartum dosed, postpartum dosed, and pre- and postpartum dosed cows.

Figure 2. Milk production from wk 1 to 13 of lactation for control, prepartum dosed,

postpartum dosed, and pre- and postpartum dosed cows......................................................... 68

Figure 3. Treatment by parity interaction $(\mathrm{P}<0.05)$ for milk yield for control, prepartum dosed, postpartum dosed, and pre- and postpartum dosed cows. ........................................... 69

Figure 4. Treatment by parity interaction $(\mathrm{P}<0.05)$ for peak milk for control, prepartum dosed, postpartum dosed, and pre- and postpartum dosed cows. .......................................... 70

Figure 5. Treatment by parity interaction $(\mathrm{P}<0.05)$ for milk protein percentage for control, prepartum dosed, postpartum dosed, and pre- and postpartum dosed cows. ....... 71 


\section{CHAPTER 1: INTRODUCTION}

The transition from a dry cow diet to a lactating cow diet is most important in the first 30 days in milk (DIM) as the rumen microbes adjust from a predominantly hay diet to a diet consisting of $\geq 45 \%$ concentrates (Counotte et al., 1983). Due to the change in diet and increase in energy requirement for fresh cows, there is a high risk for metabolic conditions, such as ketosis, sub-acute rumen acidosis (SARA), and displaced abomasum within the first 30 DIM. In an attempt to decrease the incidence of these unfavorable metabolic diseases, producers have traditionally used step-up diet transition strategies, feed additives, and ionophores (Klieve et al., 2003). Generally, the preferred industry practice is to gradually introduce grain to the diet over a few weeks in order for rumen microbes to adapt to the high grain diet; however, with the total mixed ration (TMR) system, this is less practical and producers prefer to minimize the number of TMR used. Direct-fed microbials (DFM) are a novel option for decreasing the occurrence of metabolic conditions during the transition period and postpartum. In recent years, their use has increased in part due to the unfavorable view of antibiotic-use by the general public (Martin and Nisbet, 1992; Zebeli et al., 2012). Dosing of DFM holds promise for decreasing the amount of time ruminants spend transitioning from a high forage diet to a low forage diet (Klieve et al., 2003). 
Megasphaera elsdenii is a promising DFM in production practices due to its ease of establishment in the rumen and its lactic-acid utilizing capabilities (Klieve et al., 2003; Henning et al., 2010a). The lactic acid-utilization of M. elsdenii has the capability of decreasing the risk for lactic acidosis and stabilizing rumen $\mathrm{pH}$ in transition cows. In previous dairy cattle studies, lactating cows were dosed postpartum, and none of the studies investigated dosing with M. elsdenii prepartum (Hagg et al., 2010; Aikman et al., 2011; Henning et al., 2011; Zebeli et al., 2012). Establishing a viable M. elsdenii population before calving and during the transition to a lactating diet could improve animal performance and decrease metabolic risks postpartum.

The risk of metabolic disease in fresh cows is not only detrimental to cow health, but financial implications occur in the cost of treatment and loss in milk production. In addition, as the cost of concentrates increases, feed efficiency in dairy cows becomes increasingly more important. Dosing fresh cows with M. elsdenii provides an opportunity to minimize adverse effects of rapidly transitioning from a high forage diet to a high concentrate diet and increase overall lactation performance. In this thesis, performance is defined by: reduced prevalence of metabolic diseases, decreased number of days open, and increased milk production. Improved performance ultimately results in increased producer profitability. 


\section{CHAPTER 2: LITERATURE REVIEW}

\section{Transition Cows}

The transition period in dairy cattle is very important because it determines the success of the following lactation. The transition period is described as the $3 \mathrm{wk}$ prepartum through the $3 \mathrm{wk}$ postpartum and encompasses both a change in diet and an increase in energy demand for the newly lactating cow (Grummer, 1995). The $3 \mathrm{wk}$ postpartum are also associated with a 30 to $35 \%$ decrease in feed intake in both heifers and mature cows (Grummer, 1995). During this period, the combination of an increase in energy demand for milk production and lowered feed intake causes a negative energy balance (NEB) in the animal. This NEB is most severe in the first week following calving and leads to the rapid mobilization of body tissues to compensate for the energy imbalance.

"Production diseases" can arise as a result of this NEB. Some examples of "production diseases" include metabolic disorders, such as ketosis, hypocalcemia, and hypomagnesemia, as well as displaced abomasum, retained placenta, and laminitis (Mulligan and Dohery, 2008). Other factors such as facilities, grouping strategy, and heat stress also can increase the risk for developing production disease postpartum (Mulligan and Doherty, 2008). In addition, inter-relationships between metabolic diseases can increase the risk for other diseases, including infectious diseases, increased losses in milk 
yield, increased lameness, and increased the risk for intramammary infection (Mulligan and Doherty, 2008). Impaired reproductive performance, such as delayed ovulation and lowered conception, also is associated with increased metabolism of body tissue stores, a large decrease in body condition score (BCS), and NEB in the first month postpartum (Butler and Smith, 1989; Jorritsma et al., 2003). Along with NEB, periparturient cows can develop sub-acute rumen acidosis (SARA) due to the abrupt change to a high-grain lactating diet (Enemark, 2009).

Production diseases associated with transition cows are costly to dairy producers due to milk production losses, premature culling, veterinary care, decreased feed efficiency, and increased death loss. Economic losses associated with SARA alone cost between $\$ 500$ million and $\$ 1$ billion annually (Enemark, 2009). Proper management of transition cows can, therefore, increase the profitability of dairy producers.

\section{Feeding the Transition Cow}

\section{A. Rumen Microbial Population}

The microbial population of the rumen consists of 4 major microbe domains: archaea, bacteria, protozoa, and fungi. These microbes are responsible for the conversion of feedstuffs into absorbable nutrients such as volatile fatty acids (VFA) and, therefore, have a significant role in animal performance. The 3 main groupings of bacteria in the rumen are proteolytic, cellulolytic, and amylolytic. The rumen microbial community varies from animal to animal (Warner et al., 1962; Mohammed et al., 2012). A number of factors can alter the rumen bacterial population, such as the amount of time between 
feedings (Warner, 1962), fluctuations in rumen pH (Russell and Dombrowski, 1980), and the concentration of fermentation end products (Hiltner and Dehority, 1983). Changes in the diet, such as a decrease in the forage-to-concentrate ratio, also can shift the rumen bacterial community (Tajima et al., 2000; Tajima et al., 2001; Fernando et al., 2010).

\section{Effect of Changing to a High-Grain Diet}

A change in diet from a low concentrate:high forage dry cow diet to a high concentrate:low forage lactating cow diet is essential to provide the energy needed for lactation. A concern with periparturient cows transitioning to a high grain diet is the decrease in rumen $\mathrm{pH}$ associated with this type of dietary switch. This drop in $\mathrm{pH}$ is due to the rapid fermentation of soluble carbohydrates and resultant accumulation of VFA and lactic acid in the rumen. Cellulolytic bacteria (e.g., Butyrivibrio fibrisolvens, Fibrobacter succinogenes, Ruminococcus albus, and Ruminococcus flavefaciens) numbers are especially sensitive to low $\mathrm{pH}$, and F. succinogenes, $R$. albus, and $R$. flavefaciens will wash out at $\mathrm{pH}$ of 6.0, 5.9, and 6.2, respectively (Russell and Dombrowski, 1980). As a consequence of the $\mathrm{pH}$ susceptibility of cellulolytic bacteria, cellulose digestion is reduced when $\mathrm{pH}$ levels are low (Hiltner and Dehority, 1983). While the activity of cellulolytic bacteria decreases during animal adaptation to a highgrain diet, an increase in amylolytic and lactic acid-utilizing bacteria (Megasphaera elsdenii, Streptococcus bovis, Selenomonas ruminantium, and Prevotella bryantii) activity has been shown to occur (Fernando et al., 2010). 


\section{B. Rumen Fermentation}

Carbohydrates comprise between 60 to $70 \%$ of dairy cattle diets and serve as the main energy source for rumen microbes (NRC, 2001). Non-structural carbohydrates (NSC), starches, sugars, organic acids, and fructans are included at greater proportions in lactating cow diets than in dry cow diets in order to meet the higher energy demands of the lactating cow. Increasing the proportion of NSC can decrease fiber digestion and dry matter intake (DMI) (NRC, 2001). In addition, increasing NSC replaces NDF in the diet and decreases rumination, saliva production, and VFA production (NRC, 2001).

The particle size of the diet also can affect rumen fermentation. Beauchemin et al. (2003) observed a reduction in the amount of time rumen $\mathrm{pH}$ was $\leq 5.8$ when chopped hay was fed compared to ground hay. Particle size also can affect the rate of passage of digesta from the rumen, thus affecting DMI due to rumen fill and rumen $\mathrm{pH}$ due to selective retention of coarse particles (Van Soest, 1994; Allen, 1996; Gressley et al., 2011; Kammes and Allen, 2012). Grain processing, such as steam-rolling or flaking, and dietary inclusion of more rapidly fermentable sources of NSC, such as wheat, also can decrease rumen $\mathrm{pH}$ (Krause and Oetzel, 2006).

\section{Fermentation Products}

Degradation and fermentation of carbohydrates, in conjunction with nitrogen sources, by rumen microbes provides the microbes with the adenosine triphosphate (ATP) needed for cell growth and production of VFA and lactate. The VFA are the primary energy source for the ruminant animal. The 3 main VFA produced by microbial fermentation are acetate, propionate, and butyrate. Acetate is converted to acetyl-coA and 
used in the tricholoracetic (TCA) cycle or for fatty acid (FA) synthesis in the mammary gland or adipose tissue. Propionate is a major glucose precursor and is converted to glucose in the liver during the process of gluconeogenesis. Butyrate is the preferred energy source of rumen epithelial cells, can be converted to $\beta-\mathrm{OH}$ butyrate by the rumen epithelium, and also is taken up by the mammary gland for milk fat. Lactic acid is produced by lactic acid-producing bacteria in 1 of 2 isomers: $\mathrm{L}(+)$ lactate and $\mathrm{D}(-)$ lactate ( 50:50) (Nagaraja and Titgemeyer, 2007). An accumulation of these fermentation end products, especially $\mathrm{D}$-lactate, may cause a depression in rumen $\mathrm{pH}$, if their production exceeds absorption.

\section{Rumen pH}

The typical rumen $\mathrm{pH}$ of grain-adapted cattle ranges from 5.8 to 6.5 , and a $\mathrm{pH}$ of 6.0 to 6.5 is considered ideal (Nagaraja and Titgemeyer, 2007). Rumen $\mathrm{pH}$ is affected by a number of feeding conditions, including the type and amount fermentable carbohydrate intake, the buffering capacity of the animal, and rate of utilization and absorption of VFA and lactic acid (Nagaraja and Titgemeyer, 2007). Grain processing, type of grain, particle size, amount and source of NDF, slug feeding of grain, TMR sorting, and DM of the feed can all alter rumen $\mathrm{pH}$ by increasing acid production or by decreasing acid removal and buffering capacity.

Increased production of VFA and lactate can depress rumen $\mathrm{pH}$ (Owens et al., 1998). Lactate decreases rumen $\mathrm{pH}$ more rapidly than VFA and other rumen acids due to its lower pKa and is especially important in lactic acidosis (Owens et al., 1998). The total ruminal VFA and molar proportions of VFA are altered by transition to a high-grain diet. 
Both the total molar amount of VFA and the molar proportion of propionate tend to be greater with feeding high-grain versus high-forage diets (Tajima et al., 2000; Penner et al., 2009). The molar proportion of acetate and the acetate-to-propionate ratio are lower in animals fed high-grain diets (Penner et al., 2009). The increase in VFA production increases the rate of absorption of VFA across the rumen epithelium, due to the concentration-dependency of VFA absorption. The VFA are passively absorbed across the rumen epithelium in the protonated form, and as a result, a decrease in rumen $\mathrm{pH}$ also increases the rate of absorption (Dijkstra et al., 1993; Owens et al., 1998). Feeding a highly fermentable diet also has been shown to increase the expression of VFA anion transporters, and the increase in transporter expression occurs before the morphological changes in rumen papillae (Penner et al., 2011). The increase in VFA associated with the transition from high forage to a high grain diet promotes the growth of rumen papillae (Kleen et al., 2003). Total elongation of rumen papillae may take 4 to $6 \mathrm{wk}$; if the shift from the high forage diet to the high grain diet is too abrupt, the papillae may not have enough time to increase in surface area to allow for optimal VFA absorption (Hutjens, 1996).

\section{Ruminal Acidosis}

Ruminal acidosis is classified as either sub-acute (SARA) or acute. The SARA and acute acidosis are defined as a depression in rumen $\mathrm{pH}$ below 5.6 and 5.2, respectively (Owens et al., 1998). This drop in $\mathrm{pH}$ with acute acidosis is due to an accumulation of lactic acid in the rumen (Nagaraja and Titgemeyer, 2007). However, SARA is described as a depression in ruminal $\mathrm{pH}$ due to VFA accumulation, with very 
little lactate detected in the rumen (Krause and Oetzel, 2006; Nocek, 1997). The SARA is regarded as more economically important than acute acidosis because SARA-affected animals may not appear sick but have decreased feed intake and production (Slyter, 1976; Owens et al., 1998).

\section{Rumen Microorganism Changes Associated with Acidosis}

In order to treat and ultimately prevent the incidence of ruminal acidosis, the cause of the accumulation of organic acid in the rumen and resultant $\mathrm{pH}$ depression must be identified. In dairy cattle, the adaptation to a high-concentration diet around calving increases the availability of readily fermentable carbohydrates in the rumen. This increase in starch concentration promotes amylolytic microbe activity, such as that of Streptococcus bovis and Selenomonas ruminantium (Nagaraja and Titgemeyer, 2007). S. ruminantium, S. bovis, and Lactobacillus spp. have both fast growth rates and the ability to rapidly degrade starch and soluble sugars, which results in the accumulation of VFA and lactic acid (Nagaraja and Titgemeyer, 2007). Goad et al. (1998) observed a 10-fold increase in ruminal Lactobacillus numbers in grain-adapted compared to hay-adapted steers, and Fernando et al. (2010) observed a 2-fold increase in S. bovis at the beginning of the step-up regimen and a 30 -fold increase in S. ruminantium during the entire adaptation period to a high-grain diet.

Streptococcus bovis is a major lactate-producer and is relatively tolerant of low rumen $\mathrm{pH}$ (Russell and Hino, 1985). In the presence of excessive substrate, S. bovis proliferates rapidly and produces lactic acid (Russell et al., 1981). Lactate production in S. bovis is fructose 1,6-disphosphate dependent, and lactate dehydrogenase is feed- 
forward activated by fructose 1,6-diphosphate (Bond and Russell, 1996). The increase in lactic acid production as the $\mathrm{pH}$ declines further promotes acidosis and will eventually lead to acute acidosis (Russell and Hino, 1985; Asanuma et al., 1997; Nagaraja and Titgemeyer, 2007). S. ruminantium both produces and utilizes lactic acid (Nagaraja and Titgemeyer, 2007). Strains of S. ruminantium that utilize lactate are classified as spp. lactilytica, while the strains that do not utilize lactate are grouped in the subspecies ruminantium (Nagaraja and Titgemeyer, 2007). S. ruminantium spp. ruminantium is the predominant organism, whereas spp. lactilytica accounts for less than $1 \%$ of the total $S$. ruminantium population (Yoshii et al., 2003). As rumen $\mathrm{pH}$ falls, most ruminal bacteria are inhibited and the acid-tolerant anaerobic Lactobacilli predominate (Slyter, 1976; Nagaraja and Titgemeyer, 2007). In addition to the lactic acid-producing bacteria, holotrich protozoa also are capable of producing lactate (Morgavi et al., 1994).

Rumen microorganisms, such as M. elsdenii, $P$. shermanii, and S. ruminantium spp. lactilytica, utilize lactic acid and help to stabilize the rumen $\mathrm{pH}$ (Nocek, 1997). These organisms are responsible for the further metabolism of the fermentation intermediate, lactate, to VFA (Nagaraja and Titgemeyer, 2007). Based on cultured bacteria, M. elsdenii is the major lactate utilizer and has a vital role in the prevention of lactate accumulation in the rumen, as $M$. elsdenii utilizes 60 to $80 \%$ of the lactate produced in the rumen of cattle (Counotte et al., 1981). Both the L- and D- forms of lactate can be used by $M$. elsdenii, and it is the only characterized rumen microorganism known to ferment lactate to propionate via the acrylate pathway (Counotte et. al., 1981). S. ruminantium spp. lactilytica utilizes less lactate and metabolizes only D-lactate, as it possesses little to no lactate racemase or L-lactate dehydrogenase (Asanuma and Hino, 
2005). Bacteria are not the only rumen microorganisms that utilize lactic acid;

entodiniomorphid protozoa also are capable of using lactic acid (Newbold et al., 1987; Morgavi et al., 1994). The entodiniomorphid protozoa produce propionate and butyrate from lactate (mostly L-lactate) (Morgavi et al., 1994).

\section{Prevention of Acidosis}

The ultimate goal in any business is to prevent problems before they occur. The dairy industry benefits from feeding management practices that aim to prevent metabolic diseases, such as acidosis. Acidosis is especially important to prevent as it affects feed intake, rumen fermentation products, rumen microflora, milk production, and can increase the risk for diarrhea, laminitis, and liver abscesses (as cited in Plaizier et al., 2009). The traditional management practice to prevent ruminal acidosis is to gradually introduce dairy cattle to a higher concentrate diet; however, grouping strategies (limiting number of groups and group moves) and feeding management practices (e.g., TMR usage) limit using this approach today (Meissner et al., 2010). Controlling acidosis via a method other than a feed-adaptation period would likely be more economical because less forage would be fed and an earlier increase in concentrate might boost milk production.

\section{Buffers}

Feed, ammonia, and saliva can all function as ruminal buffers by resisting a change in rumen $\mathrm{pH}$ (Allen, 1997). The buffering capacity of ingested feed produced in 
the rumen is optimal when the rumen $\mathrm{pH}$ is low, but negligible at normal rumen $\mathrm{pH}$ (Allen, 1997). Ammonia produced from protein degradation has some buffering capacity, but it is rapidly absorbed through the rumen epithelium (Allen, 1997). Saliva production is directly correlated with the amount of forage in the diet, and saliva flow and buffering capacity is greatly decreased when forage content is low (<30\% forage) (Erdman, 1988).

The inclusion of dietary buffers, such as bicarbonate salts, is a regular practice in both feedlot and dairy cattle nutrition, in which low forage diets are fed to increase gain or milk production. Adequate dietary buffers should be water-soluble and have a pKa value similar to the physiological pH of the rumen (Enemark, 2009). The palatability and effectiveness of mixing a buffer into a ration should also be considered because this could decrease feed intake (Erdman, 1988). The NRC (2001) suggests that dietary buffers be fed at 0.6 to $0.8 \%$ of DMI and will benefit early lactation cows fed a high concentrate diet the most.

\section{Feeding Management}

In order to achieve optimal milk production and lessen NEB, early lactation diets are formulated with a greater proportion of NFC and less fiber. Motivation for reducing the percentage of NDF is to increase digestibility and DMI. The NDF is, on average, less digestible than NFC and can negatively affect DMI because of rumen fill (NRC, 2001). Increasing dietary NDF, forage NDF (fNDF), and the amount of digestible organic matter (OM) of forages positively influences ruminal pH (Zebeli et al., 2006). Firkins et al. (2001) suggested that, in addition to ruminal $\mathrm{pH}$, chewing time and the acetate-topropionate ratio also are correlated with the dietary fNDF-to-NSC ratio. Reducing the 
percentage of fiber can have an adverse affect on rumen health and ruminal $\mathrm{pH}$, due to a reduction in buffering capacity (ie. chewing and saliva production) (NRC, 2001; Zebeli et al., 2006). Therefore, decreasing the NDF fraction predisposes early lactating cows to SARA. The NRC (2001) recommendations for NDF are $25 \%$ of dietary DM and $19 \%$ of the total dietary DM from fNDF when the NFC is $44 \%$ of dietary DM. The source and physical form of the fiber and feed sorting by cows should be evaluated and considered when adjusting actual dietary recommendations of NDF and fNDF.

Both the chemical characteristics (i.e., NDF) and the physical characteristics of the fiber are important to consider when the forage-to-concentrate ratio is decreased (Mertens, 1997). The particle size and density of the fiber source can affect ruminal fermentation, animal health, and milk fat yield regardless of the NDF amount (Mertens, 1997). The ability of fiber to influence chewing activity and the density of the ruminal fiber mat is defined as physically effective NDF (peNDF) and is measured as the product of NDF content and the physically effective factor (Mertens, 1997). The effects of peNDF on ruminal $\mathrm{pH}$, chewing activity, and fiber digestibility appear to be inconsistent and variability between techniques used to measure peNDF creates difficulty in establishing dietary requirements for peNDF (Beauchemin et al., 2003; Yang and Beauchemin, 2006; Zebeli et al., 2006). The suggested amount of peNDF is 19 to $22 \%$ of DMI based on the particle retention by a $1.18 \mathrm{~mm}$ screen to maintain an average ruminal pH of 6.0 (Beauchemin et al., 2003; Zebeli et al., 2006). The variability of peNDF in nonforage fiber sources should be considered when they are included at high levels in dairy cow diets because they are less effective at stimulating chewing and maintaining ruminal pH (Allen, 1997). 


\section{Environmental Stress (Heat Stress and Grouping)}

Environmental conditions can influence the incidence or severity of ruminal acidosis by affecting feed intake and behavior. Heat stress and facility conditions such as stall comfort, overcrowding, and bunk management can all alter cow behavior and negatively impact cow health (Stone, 2004). Grouping strategy can affect DMI due to cow comfort and competition for feed and water (Grant and Albright, 2001). Konggaard and Krohn (1978) (as cited in Grant and Albright, 2001) noted an increase in DMI and milk production by primiparous cows when they were housed separately from multiparous cows, likely due to less competition at the feed bunk and decreased stress. Decreasing feed bunk space increases feeding competition and reduces feeding time and intake (Friend et al., 1977; Grant and Albright, 2001). Heat stress depresses feed intake by altering cow behavior and meal patterns (Sniffen et al., 1993). Altered feeding patterns caused by thermal stress include "slug-feeding" (Mallonée et al., 1985), reduced rumination (Collier et al., 1982), and decreased DMI (McGuire et al., 1989; Lough et al., 1990). The DMI of thermal stressed cows is reported to be 3 to $4 \mathrm{~kg} / \mathrm{d}$ lower than that of thermal comfort cows (Lough et al., 1990; McGuire et al., 1989). The reduction in DMI associated with an increase in ambient temperature is important to consider for early lactation cows that already have depressed intakes and are at elevated risk for metabolic disease (Grant and Albright, 1995). In the study by Mishra et al. (1970), when cows were subjected to the "cool" condition of $18.3^{\circ} \mathrm{C}$ and $50 \%$ humidity compared to the "hot" condition of $29.4^{\circ} \mathrm{C}$ and $85 \%$ humidity, mean rumen $\mathrm{pH}$ declined from 6.3 to 5.9, respectively. A reduction in the time spent lying in free stalls also is associated with an increase in ambient temperature (Overton et al., 2002). Due to the alterations in feeding 
behavior by heat stress, increasing the peNDF and decreasing NSC during the summer may help reduce the risk of SARA (Stone, 2004). Concurrently, replacement of some NSC with fat supplementation will increase the energy density of the diet when DMI is depressed during heat stress (Wang et al., 2010). The feeding of yeast culture during periods of heat stress also may improve feed efficiency and milk production (Schingoethe et al., 2004; Bruno et al., 2009). Proper environment and facility management, in addition to nutrition, are important to minimize the incidence of metabolic disease, particularly SARA (Stone, 2004).

\section{Ionophores}

Ionophores are a type of chelating agent that bind monovalent ions, such as sodium and potassium (Van Soest, 1994). The primary function of ionophores is to alter rumen bacterial populations by inhibiting the growth of some ruminal bacteria, such as $S$. bovis and Lactobacillus spp. (Dennis and Nagaraja, 1981; Chow and Russell, 1990). Two commonly used ionophores in dairy cattle rations are monensin and lasalocid. Monensin and lasalocid penetrate the cell membrane bacteria and cause a disruption in the efflux of ions (Russell, 1987). Ionophores are proposed to prevent or decrease the severity of ruminal acidosis by inhibiting lactate-producing bacteria, thereby reducing lactate production (Enemark, 2009). The results of monensin supplementation in studies using lactating cows vary. In a lactating cow study, Osborne et al. (2004) observed a 19.7\% increase in total tract fiber digestibility with monensin supplementation (22 mg of monensin/kg of TMR), but monensin had no effect on DMI, milk yield, or milk 
composition. Dietary monensin inclusion does not appear to significantly affect ruminal pH characteristics during SARA conditions in dairy cows (Mutsvangwa et al., 2002; Osborne et al., 2004).

The function of ionophores in altering rumen fermentation characteristics is inconsistent. Sauer et al. (1989) observed an increase in the molar proportions of propionate and valerate and a decrease in acetate and butyrate with the addition of monensin to the diet of lactating dairy cows. A similar increase in propionate with monsenin addition was observed during in vitro incubations with corn (Russell and Strobel, 1988). In contrary, the studies performed by Oelker et al. (2009), Mathew et al. (2011), and Reveneau et al. (2012) did not observe an increase in the propionate or a decrease in acetate and butyrate with the addition of monensin. The decreased plasma $\beta$ hydroxybutyrate (BHBA) concentrations in postpartum cows fed a monensin-containing ration suggest monensin supplementation improved energy balance (Sauer et al., 1989; Mullins et al., 2012). Despite a decrease in plasma BHBA concentrations in monensinsupplemented cows, milk production was not significantly improved (Sauer et al., 1989; Mullins et al., 2012). The potential of ionophores to increase the performance of lactating dairy cows is most likely related to increased feed efficiency than a change in the acetate:propionate ratio (Ipharraguerre and Clark, 2003). The benefits of ionophore usage in dairy cattle may also vary depending on dietary characteristics, environmental conditions, and production level of cows. 


\section{Direct-Fed Microbials}

The DFM are live, naturally occurring microorganisms, such as yeast, fungi, and bacteria, which beneficially alter microorganism populations (Yoon and Stern, 1995; Ghorbani et al., 2002). Interest in the effect of DFM on animal performance has increased as concern of antibiotic-use in the food-animal industry has grown (Martin and Nisbet, 1992). Although the definite mechanisms of action by DFM have not been established, there are some suggested modes. Yoon and Stern (1995) suggested that DFM function by modifying microbial populations of the rumen or lower gut, altering rumen microbial fermentation, increasing the intestinal nutrient flow, improving diet digestibility, and enhancing host immunity. Lactate-producing bacteria, such as Lactobacillus, have been used in commercially available DFM products (Kung, 1999), but variable animal responses have occurred (Yoon and Stern, 1995). The concept of using lactate-producing bacteria is to adapt the ruminal microbe populations to the presence of lactic acid (Ghorbani et al., 2002). The use of lactate-utilizing bacteria, such as M. elsdenii, is to prevent the accumulation of lactic acid (Kung and Hession, 1995). Ghorbani et al. (2002) observed an increase in acetate concentration and an indication of decreased incidence of acidosis in feedlot cattle with supplementation of a combination of Propionibacterium and Enterococcus.

Certain yeasts have been shown to benefit cellulolysis and growth of cellulolytic bacteria. Williams et al. (1991) reported an increase in milk yield with dietary inclusion of Saccharomyces cerevisiae. There is some uncertainty of the viability and ability of yeasts to multiply in the rumen due to anaerobiosis (Brown and Nagaraja, 2009). 
Inclusion of fungal cultures may improve fiber digestibility and increase rumen $\mathrm{pH}$ by stimulating the growth of cellulolytic and lactate-utilizing rumen bacteria (Brown and Nagaraja, 2009). Aspergillus oryzae and S. cerevisia have been shown to decrease lactic acid accumulation by stimulating lactate utilization by S. ruminantium in pure culture (Martin and Nisbet, 1992). Overall, production results with fungal DFM and yeasts have been inconsistent (Beauchemin et al., 2000; Brown and Nagaraja, 2009).

Many DFM are commercially available that hold promise for enhancing animal performance. Supplementation of DFM is typically most beneficial to animals under stress or with lowered immune responses, such as early lactation cows, high producing cows, or clinically ill cows that have been given antibiotics (Beauchemin et al., 2000; Krehbiel et al., 2003; Nocek et al., 2003). In addition, DFM may enhance fiber digestibility; which is especially important in the summer when fiber digestibility can be compromised because of heat stress (Beauchemin et al., 2003). However, the use of DFM as a means to alter ruminal microbial fermentation has proven to be variable. Further research into the activity of DFM and the optimal conditions at which they operate is needed (Yoon and Stern, 1995; Krehbiel et al., 2003; Brown and Nagaraja, 2009).

\section{Megasphaera elsdenii}

Megasphaera elsdenii is an obligate anaerobe bacterium found in the rumen of ruminant animals. M. elsdenii is a predominant lactate-utilizer and is dependent on the products of polymer hydrolysis, such as soluble sugars and lactate, performed by other rumen microbes (Marounek et al., 1989). M. elsdenii grows well in vitro on a variety of substrates (glucose, fructose, maltose, glucosamine, mannitol, lactate, and pyruvate) and 
produces different end products from glucose (predominantly butyrate) than lactate, and end products are variable by strain (Marounek et al., 1989). Megasphaera elsdenii differs from other lactate-utilizing bacteria because it lacks the catabolite repression by glucose and maltose that hinders lactate utilization in similar organisms (Hino and Kuroda, 1993). The ability of M. elsdenii to preferentially utilize lactate has peaked interest in using this organism as a DFM for grain-fed cattle.

\section{A. Metabolism of Lactate by M. elsdenii}

Over $60 \%$ of the lactate produced in the rumen is metabolized by M. elsdenii and includes both the L- and D- forms of lactate (Counotte et al., 1981). Megasphaera elsdenii possesses 2 possible pathways for fermenting lactate and these pathways are based upon the isoform of lactate (D- or L-) present. The conversion of L- lactate to Dlactate by lactate racemase (LR) is readily reversible and activity of LR is inducible by the presence of lactate (Hino and Kuroda, 1993; Hino et al., 1994). D-lactate is constitutively converted to pyruvate via NAD-independent D-lactate dehydrogenase (iDLDH) (Hino and Kuroda, 1993; Hino et al., 1994). The end products of D-lactate fermentation are butyrate and acetate via acetyl-CoA.

The L-lactate is converted to propionate via the acrylate pathway with acrylylCoA as an intermediate (Hino and Kuroda, 1993). Megasphaera elsdenii is the only known rumen microbe to use this pathway to convert lactate to propionate (Nagaraja and Titgemeyer, 2007). Of the amount of lactate fermented, over $70 \%$ is converted to propionate via the acrylate pathway (Counotte et al., 1981). 
The directionality of lactate through the 2 lactate-utilization pathways is both concentrate- and $\mathrm{pH}$-dependent. In batch culture, where lactate is present in excess, $M$. elsdenii principally produced propionate, along with acetate and butyrate. Under carbonlimited conditions, in which minimal lactate was present, acetate and butyrate were formed but not propionate (Prabhu et al., 2012). The lack of sufficient lactate flux to drive the formation of lactyl-CoA from L-lactate and subsequent formation of acrylylCoA explains why M. elsdenii grown on only glucose failed to produce propionate from the acrylate pathway (Counotte et al., 1981; Prabhu et al., 2012). In contrast, the reaction of D-lactate to pyruvate via iD-LDH is favored when lactate concentration is low, and acetate and butyrate are the principal products (Hino et al., 1994). M. elsdenii will preferentially ferment lactate until low concentrations, 1 to $2 \mathrm{mM}$, before it utilizes glucose as a substrate (Hino et al., 1994). Counotte et al. (1981) observed that as rumen $\mathrm{pH}$ decreases, more butyric acid is fermented from DL-lactate; therefore, the fermentation of DL-lactate to butyrate is $\mathrm{pH}$-dependent (most produced at $\mathrm{pH} 5.25$ to $6.0)$.

An increase in the ruminal M. elsdenii population during the transition period in dairy cattle has the potential to not only prevent acidosis but also improve energy balance by converting the excess lactate to propionate. The increase in lactate production by $S$. bovis and Lactobacillus spp. associated with the transition to a high-grain diet may provide the lactate flux necessary for the production of propionate via the acrylate pathway (Counotte et al., 1981). Microbial propionate production influences the energy balance of transition cows because $80 \%$ of the propionate produced in the rumen is converted to glucose in the liver through gluconeogenesis (Allen et al., 2009). The supply 
of propionate to the liver is important for transition cows at risk for NEB, ketosis, and fatty liver, and increasing propionate production may reduce the incidence and severity of these metabolic diseases (Wang et al., 2012).

\section{B. In vitro Trials}

The lactate fermenting ability of $M$. elsdenii has been studied in cultures for many years. Some strains of $M$. elsdenii have proven better at preventing lactic acid accumulation and an excessive drop in $\mathrm{pH}$ than others. The M. elsdenii B159 strain studied by Kung and Hession (1995) prevented lactate accumulation and pH drop when incubated in mixed rumen culture with highly fermentable carbohydrates (comprised of 55\% starch and $26 \%$ glucose). The $\mathrm{CH} 7$ and $\mathrm{CH} 4$ strains studied by Henning et al. (2010b) were the most efficient in utilizing lactic acid and maintaining lactic acid concentration below $10 \mathrm{mmol} / \mathrm{L}$ in comparison to the other 9 strains studied, when incubated in batch cultures of rumen fluid with added maltose as substrate. The amount of time the culture $\mathrm{pH}$ stayed $<6.0$ was also significantly lower for strains $\mathrm{CH} 7, \mathrm{CH} 3$, and $\mathrm{CH} 4$.

The end products of fermentation by M. elsdenii also vary by strain and by substrate. Marounek et al. (1989) studied 4 different strains of M. elsdenii, and the production of metabolites varied by strain and by amount of glucose added to the lactate medium. In lactate medium, strains LC1 and AW106 produced mostly acetate and propionate; strain L8 produced almost equal amounts of acetate, propionate, and butyrate; and butyrate was the predominate metabolite produced by strain $\mathrm{J} 1$. As glucose was added to the lactate medium, the propionate produced by all 4 strains declined and 
butyrate production increased. In a study by Kung and Hession (1995), cultures with the B159 strain of $M$. elsdenii that were incubated in ruminal fluid inoculated with substrate containing $55 \%$ soluble starch, $26 \%$ glucose, $6 \%$ cellulose, $7 \%$ cellobiose, and $6 \%$ trypticase (by weight) had lower concentrations of acetate and propionate and higher concentrations of butyrate than the control. Similarly, Forsberg (1978) observed an absence of detectable levels of propionate when strain B159 was grown in low glucose medium, although acetate, propionate, butyrate, and valerate were produced when grown in low lactate medium. The NIAH 1102 strain of M. elsdenii produces mainly acetate and butyrate when grown on glucose only, with minimal propionate production (Hino and Kuroda, 1993; Hino et al., 1994). When this particular strain was grown on either D- or L-lactate, similar quantities of acetate, propionate, and butyrate were produced. In addition, when acrylate was added to either the L-lactate or the glucose substrate, propionate was the predominate metabolite produced (Hino and Kuroda, 1993). When lactate was the sole carbon source strain, YE34 primarily produced butyrate and valerate (Ouwerkerk et al., 2002). Horn et al. (2009) reported that strain CH4 (also known as NCIMB 41125) converted lactate to mainly acetate, and the proportions of butyrate, valerate, and propionate produced were dependent on $\mathrm{pH}$ and dilution rate.

Of all the strains of M. elsdenii studied in vitro, the NCIMB 41125 strain has shown the most promise for use as a DFM to prevent or alleviate ruminal acidosis. It has a high growth rate $(0.94 / \mathrm{h})$ and a long survival rate on medium (20 d) (Horn et al., 2009). This biomass accumulation could provide protection from harsh environmental factors, such as oxygen exposure, when used in a commercial application (Meissner et al., 2010). This specific strain is relatively resistant to low $\mathrm{pH}$ and is able to produce fermentation 
end products at $\mathrm{pH}$ below 5.5, even though a sharp decline in growth is observed between pH 5.5 and 6.0 (Horn et al., 2009). The robustness and lactic acid utilization ability of $M$. elsdenii NCIMB 41125 has led to research aimed at evaluating the effects of administering this strain to animals at risk for developing ruminal acidosis.

\section{Establishment of M. elsdenii in vivo}

In order for a DFM to be efficient, the microbe must first be readily established in the rumen. Studies on the establishment of M. elsdenii in ruminant animals have shown that this microbe can be successfully established in the rumen. In the Kileve et al. (2003) study with beef steers inoculated via rumen cannula with $5.5 \times 10^{11} \mathrm{cfu}$ of $M$. elsdenii, the rumen population of M. elsdenii immediately after inoculation was $>10^{6}$ cell equivalents $(\mathrm{CE}) \mathrm{ml}^{-1}$ and increased throughout the trial to an excess of $10^{8} \mathrm{CE} \mathrm{ml}^{-1}$. Prior to inoculation or grain introduction, M. elsdenii was not detectable in any of the steers, inoculated or control. The average density of $M$. elsdenii detected in the control steers did not surpass $10^{4} \mathrm{CE} \mathrm{ml}^{-1}$ before $\mathrm{d} 12$ but then increased to similar abundance as inoculated cows by d 21 (Klieve et al., 2003). The inoculated population of $M$. elsdenii established 5 to $7 \mathrm{~d}$ sooner in the rumen than the wild type population (Klieve et al., 2003). In the study by Henning et al. (2010a), the rumen population of $M$. elsdenii was higher in steers inoculated with $4 \times 10^{6} \mathrm{cfu} / \mathrm{ml}$ M. elsdenii $\mathrm{CH} 4$ (NCIMB 41125$)$ than control populations until $5 \mathrm{~d}$ after dosing, at which time control populations caught up to the inoculated. Due to the rapid establishment of $M$. elsdenii in the rumen of grain-fed animals, it holds promise for use as a DFM for ruminants transitioning from high forage to high grain diets. 
D. Beef Cattle and Sheep

\section{Beef Cattle}

Klieve et al. (2003) studied the establishment of M. elsdenii and Butyrivibrio fibrisolvens in 10 Hereford steers during the transition from a high forage diet to a highgrain end diet of $75 \%$ rolled barley. Grain adaptation was implemented in 3 steps; the first 2 days steers received $45 \%$ rolled barley followed by 2 days of $60 \%$ rolled barley, and finally $75 \%$ rolled barley for the remainder of the $22 \mathrm{~d}$ experiment. All of the diets were balanced with paspalum hay. Five of the steers were inoculated via rumen cannula with $500 \mathrm{~mL}$ of $5.5 \times 10^{11} \mathrm{cfu}$ M. elsdenii YE34 and $3 \times 10^{12}$ cfu Butyrivibrio fibrisolvens YE44 and the remaining 5 were control steers. Prior to inoculation or grain introduction, M. elsdenii was not detected in any of the steers, but it increased throughout the study. Although M. elsdenii was present in both treatment groups, the M. elsdenii density in the rumen of uninoculated steers did not reach similar levels to those of the inoculated steers until $21 \mathrm{~d}$ after grain introduction. Despite the successful establishment of M. elsdenii, there were no differences between the inoculated and control steers in feed intake, rumen $\mathrm{pH}$, or lactic acid concentration. The lactate concentration for all animals did not rise above $2 \mathrm{mmol} / \mathrm{L}$ and rumen $\mathrm{pH}$ remained above 5.6 for all steers. Although VFA did not differ by M. elsdenii inoculation, grain introduction caused a minor decrease in acetate and a doubling of propionate and butyrate concentrations in all animals.

In the study by Henning et al. (2010a), 14 beef steers were administered with

either control (no dose), low $\left(1.72 \times 10^{9} \mathrm{cfu}\right)$, medium $\left(1.72 \times 10^{10} \mathrm{cfu}\right)$, or high $\left(1.72 \times 10^{11}\right.$ cfu) doses of M. elsdenii NCIMB $41125(\mathrm{CH} 4)$ and transitioned to a $94 \%$ concentrate diet in a 5 step-up program over $20 \mathrm{~d}$. Rumen $M$. elsdenii counts did not differ between 
the 3 M. elsdenii dosages. The control steers had lower M. elsdenii counts in the first 2 to $3 \mathrm{~d}$ after inoculation and, subsequently, had higher lactic acid concentrations. Total VFA concentrations did not differ between inoculated and control steers, but inoculated steers tended to have high butyrate and acetate and lower propionate concentrations. The shift towards more butyrate may be indicative of the rumen $\mathrm{pH}$ being near the "propionate to butyrate shift" that occurs at lower $\mathrm{pH}$.

McDaniel et al. (2009) evaluated the effects of administration of M. elsdenii in steers faced with an abrupt diet change. The 20 steers were divided into 4 treatment groups and were dosed with either 10,100 , or $1000 \mathrm{ml}$ of $1.62 \times 10^{8} \mathrm{cfu} / \mathrm{ml}$ of live $M$. elsdenii NCIMB 41125 or a placebo on d 2 of the experimental period. Steers were fed a flaked corn diet consisting of $34 \%$ roughage and $66 \%$ concentrate ad libitum. Although the lactic acid concentration increased and rumen $\mathrm{pH}$ declined in all animals following the diet change from 100 to $34 \%$ roughage, the lactate concentrations were lower for steers administered M. elsdenii, regardless of dosing amount, and the M. elsdenii-treated steers maintained higher rumen $\mathrm{pH}$ in the $24 \mathrm{~h}$ after the diet change than the placebo steers.

Leeuw et al. (2009) studied the effect of dosing M. elsdenii on the performance of steers fed low roughage $(2 \%)$ or high roughage $(8 \%)$ diets. Half of the steers received a 200-ml dose of $10^{9} \mathrm{cfu} / \mathrm{ml}$ M. elsdenii NCIMB 41125 and half received a 200-ml dose of water. Steers in both of the dosing treatments were further divided in half and received either the low or high roughage diet. Neither differences in average daily intake and overall average daily gain (ADG) nor carcass characteristics differed between treatments. Dosed steers had better performance as indicated by a lower feed-to-gain ratio and higher 
ADG in the few weeks immediately post the adaptation period. This improvement in animal performance coincided with a reduced tendency of morbidity, other than diarrhea and bloat. In addition, steers on the low roughage diet had significantly lower incidences of diarrhea and bloat when dosed with M. elsdenii.

Drouillard et al. (2012) evaluated the effect of dosing steers with M. elsdenii NCIMB 41125 in 2 adaptation periods of varying length. Half of the steers were dosed with $200 \mathrm{ml}$ of inoculum containing $10^{11} \mathrm{cfu}$ M. elsdenii cells or a placebo; half of the steers in each of these 2 treatments were enrolled in either an 8- or 17-d transition period, containing 3 or 5 steps, respectively. The initial diets in both transition periods consisted of $45 \%$ roughage and $55 \%$ concentrate, and the final diets consisted of $6 \%$ roughage and 94\% concentrate. Feed intake, body weight (BW), and ADG did not differ by treatment. Carcass characteristics also did not differ by treatment; however, there was a trend for greater carcass-adjusted ADG and hot carcass weight in the inoculated steers.

\section{Sheep}

In the second part of the Henning et al. (2010a) study, 24 wether lambs were divided into 4 treatment groups in a $2 \times 2$ factorial design. The wethers were either drenched with $200 \mathrm{ml}$ of $10^{11} \mathrm{cfu}$ M. elsdenii NCIMB 41125 or not drenched and were fed forage ad libitum or restricted-fed forage. The amount of concentrate consumed did not differ between the ad libitum or restricted-fed forage treatments, but the sheep drenched with $M$. elsdenii consumed $11 \%$ more concentrate from d 1 to slaughter than their placebo-drenched counterparts and consumed less forage. Despite the lower forage intake by the drenched wethers, they had less visual signs of diarrhea in the first few 
weeks of concentrate feeding, and the decline in rumen $\mathrm{pH}$ was less. Lactic acid accumulation in the first 2 to $3 \mathrm{~d}$ after also was less for the drenched wethers. Although the concentrate intake was higher in the drenched wethers, there were no differences for ADG or dressing percentage between the control and M. elsdenii drenched animals.

Henning et al. (2010b) followed up in vitro work with M. elsdenii strains CH4 and CH7 in a study with 18 rumen-cannulated sheep. The sheep were administered with a $100-\mathrm{ml}$ dose containing either $10^{11} \mathrm{cfu}$ of $\mathrm{CH} 4$ or $\mathrm{CH} 7$ prior to grain introduction. Rumen $\mathrm{pH}$ in sheep inoculated with the $\mathrm{CH} 4$ strain never fell below a $\mathrm{pH}$ of 5.5 and recovered to 6.0 by $24 \mathrm{~h}$ after the induced grain challenge. Conversely, $24 \mathrm{~h}$ after the induced-grain challenge, the $\mathrm{CH} 7$ strain remained at 5.5 and the control strain was below 5.0. Lactic acid concentrations were lower for $M$. elsdenii inoculated sheep than control. The lactic acid concentration for both the $\mathrm{CH} 4$ and $\mathrm{CH} 7$ strains never went above $10 \mathrm{mmol} / \mathrm{L}$, whereas the control lactic acid concentration reached $55 \mathrm{mmol} / \mathrm{L}$ in the $12 \mathrm{~h}$ post-dosing. Feed intake was greater for sheep inoculated with $M$. elsdenii than for control. The higher feed intake is expected because the $\mathrm{pH}$ remained higher and that lactic acid concentrations were lower in the inoculated sheep.

\section{E. Dairy Cattle}

The effect of administration of Megasphaera elsdenii on dairy cattle production has been studied less extensively than that of the feedlot industry. In a study performed by Hagg et al. (2010), 60 multiparous Holstein cows were randomized based on parity and previous lactation into 1 of 4 treatment groups: low concentrate dosed (LCD), low 
concentrate control (LCC), high concentrate dosed (HCD), and high concentrate control (HCC). On d 2, 10, and 20 post-partum, the LCD and HCD cows were orally-dosed with $250 \mathrm{~mL}$ of $10^{9} \mathrm{cfu} / \mathrm{ml}$ of $M$. elsdenii. The mean rumen $\mathrm{pH}$ was similar among the $M$. elsdenii and control treatments. The lactic acid concentration was significantly higher in the HCC diet than either of the LCD or LCC treatments, but it did not differ from the high concentrate $M$. elsdenii treatment. No differences for total rumen VFA or individual VFA molar proportions between $M$. esldenii-dosed animals and control were observed. However, propionate concentration in the rumen was significantly higher in those fed the high-concentrate diets compared to the low concentrate diets. Dosing M. elsdenii did not affect yields of milk, protein, and lactose, or concentration of milk urea nitrogen. The fat percentage of cows dosed with $M$. elsdenii and fed a high concentrate diet (70\% concentrate) tended to be lower $(2.88 \%)$ than the non-dosed cows fed the same high concentrate diet (3.60\%). Dry matter intake, feed efficiency (kg milk/kg DMI), BW, and BCS did not differ with M. elsdenii dosing. Hagg et al. (2010) measured fecal score and pH on 15 and 30 DIM. Fecal score measured on 15 and 30 DIM was unaffected by $M$. elsdenii treatment, but fecal $\mathrm{pH}(P<0.05)$ were 6.62 and 6.43 for dosed and control treatments, respectively. The authors suggested that the difference in fecal $\mathrm{pH}$ was due to more ruminal fermentation of starch in the dosed versus control cows, which was supported by the lower fecal starch content for the dosed cows.

In the fresh cow study by Aikman et al. (2011), 14 multiparous, rumen-cannulated Holstein cows were enrolled in the study. On d 3 and 12 postpartum, cows were dosed via rumen cannula with either $250 \mathrm{ml}$ of $M$. elsdenii $\left(10^{10}\right.$ to $\left.10^{13} \mathrm{CFU}\right)$ or a placebo dose of autoclaved suspension. The mean rumen $\mathrm{pH}$ was similar between $M$. elsdenii and 
control treatments. However, the length of time that rumen $\mathrm{pH}$ was below 5.6 was decreased in the days immediately following dosing with $M$. elsdenii, and $\mathrm{pH}$ fluctuated less from day to day in these cows. Despite the reduced time that rumen $\mathrm{pH}$ was below 5.6, there was no difference in lactic acid concentration and total rumen VFA concentration by M. elsdenii-dosed animals compared to control animals. A treatment by day interaction for the acetate:propionate ratio did occur in which the ratio for placebo cows declined from d 4 to 15 and the M. elsdenii-dosed cows declined from d 4 to 6 but then increased from d 13 to 15 . Milk production efficiency was greater in dosed cows, almost $0.3 \mathrm{~kg} / \mathrm{kg}$ of DMI, and was a result of a decrease in DMI and concurrent nonsignificant increase in milk yield. The milk fat concentration tended to be $5.2 \mathrm{~g} / \mathrm{kg}$ lower in M. elsdenii-dosed cows than placebo cows. This reduction in milk fat could be due to the shift in ruminal fermentation products for M. elsdenii-dosed cows, such as a decrease in lipogenic acetate and an increase in gluconeogenic propionate compared to cows receiving placebo. The authors also suggested an abundance of $M$. elsdenii in the rumen could be responsible for the lower milk fat concentration as Palmonari et al. (2010) and Weimer et al. (2010) have demonstrated an inverse relationship between milk fat concentration and M. elsdenii abundance. Furthermore, several strains of M. elsdenii have been noted to produce trans-10,cis-12 conjugated linoleic acid in the rumen, which inhibits milk fat synthesis in the mammary gland (Kim et al., 2002). However, the reduction in milk fat may be better explained by a reduction in mobilization of body fat stores, as observed in the a 14-wk companion study by Aikman et al. (2009), in which high-yielding cows dosed with M. elsdenii tended to gain more weight and have reduced milk fat concentrations on an acidosis-challenge diet (39:61 forage:concentrate ratio) than 
placebo cows on the same diet. The effect of M. elsdenii, specifically strain NCIMB 41125, on milk fat concentration is still unclear. Milk protein concentration also was lower in M. elsdenii-dosed high yielding cows in the study by Aikman et al. (2009), but the reduction could be a dilution effect caused by the $2.2 \mathrm{~kg} / \mathrm{d}$ increase in milk yield for cows on the acidosis-challenge diet.

In a paired $2 \times 2$ crossover experimental design, Zebeli et al. (2012) dosed 8 primiparous Holstein cows every day for 2 periods of $21 \mathrm{~d}$ with either saline (control) or $35 \mathrm{~mL}\left(10^{8} \mathrm{cfu} / \mathrm{mL}\right)$ suspension of $M$. elsdenii. A decline in rumen $\mathrm{pH}$ in the hours postfeeding did occur for both control and M. elsdenii dosed cows, but $\mathrm{pH}$ remained $\geq 5.8$ for both. In addition, there was no treatment difference in the lactic acid concentration in $M$. elsdenii-dosed animals compared to control animals. Total rumen VFA between $M$. esldenii-dosed animals and control did not differ, but acetate, isobutyrate, and isovalerate were lower and valerate and butyrate were higher for M. elsdenii-dosed cows. Milk yield did not differ between cows inoculated with M. elsdenii and control cows. There was a tendency for lactose percentage to be lower $(P=0.06)$ and the somatic cell count (SCC) (cell/ml) to be higher $(P=0.06)$ in $M$. elsdeii-dosed cows compared to control cows. Blood was sampled on $\mathrm{d} 1,3,5,7$, and 10 of each period prior to the morning feeding and also sampled every $2 \mathrm{~h}$ after the morning feeding on $\mathrm{d} 10$. Of the metabolites measured, only the plasma nonesterified fatty acids (NEFA; lower) and cholesterol (higher) concentrations differed with $M$. elsdenii treatment. There was no treatment effect on BHBA, and BHBA concentrations increased in both groups postprandial.

Henning et al. (2011) evaluated the effects of dosing M. elsdenii to early lactation cows fed either a 60 or $70 \%$ concentrate diet. Half of the cows were dosed with $250 \mathrm{ml}$ of 
a $10^{11} \mathrm{cfu}$ suspension of $M$. elsdenii on the day of calving and on $\mathrm{d} 10$ and 20 postpartum and the other half were control cows (not dosed). Trial measurements were recorded until 80 DIM. Dry matter intake did not differ between $M$. elsdenii-dosed and control cows, but $M$. elsdenii-dosed cows tended to produce more milk. Cows dosed with $M$. elsdenii also had higher BW and BCS than control cows, and these differences were greater for cows on the higher concentrate diet $(70 \%)$. No difference in milk protein occurred between control and dosed cows. For the cows receiving the $60 \%$ concentrate diet, the $M$. elsdenii-dosed cows had significantly higher milk fat percentage than the control cows; however, milk fat percentage did not differ between control and dosed cows on the $70 \%$ concentrate diet or overall between the 2 dosing treatments.

\section{F. Summary}

Although M. elsdenii can be introduced into the rumen and establish populations capable of preventing lactate accumulation and acidosis, there is variation in animal response. Small animal numbers or a diet not sufficient enough to induce acidosis conditions may explain why some studies did not observe a difference in lactate accumulation or rumen $\mathrm{pH}$ between $M$. elsdenii-inoculated and control animals. The large individual variability in an animal's susceptibility to rumen acidosis may have been an important factor in the studies with a lower number of animals (Mohammed et al., 2012). Despite the inconsistent results in lactic acid concentration and rumen $\mathrm{pH}$ between $M$. elsdenii treated and control animals, shifts in the rumen VFA profile have occurred. Animals administered with $M$. elsdenii tended to have higher butyrate and lower acetate and propionate concentrations, which suggests the rumen $\mathrm{pH}$ is low enough to favor the 
iD-LDH pathway over the acrylate pathway. The effect of $M$. elsdenii on animal performance is unclear. Milk production and composition results are inconsistent and more research is needed. In addition, few animal trials have evaluated the effect of $M$. elsdenii administration on blood metabolites and cow health.

As evident from this discussion, rumen health has a significant impact on feed intake and subsequent animal performance. The effects of $M$. elsdenii administration have been observed in feedlot steers, wethers, and post-partum dairy cows; however, there are no published studies in which $M$. elsdenii was administered to pre-fresh cows or administered to cows pre-fresh and at calving. Previous work with dairy cows has shown little promise for M. elsdenii to increase milk yield, and Hagg et al. (2010) observed a decline in milk fat percentage in dosed cows. More investigation is needed to understand why there was a decline in milk fat percentage and no effect on milk yield. The trend for increased milk production efficiency observed by Aikman et al. (2011) in M. elsdeniidosed cows in contrast to the lack of difference between dosed and control cows observed by Hagg et al. (2010) and Zebeli et al. (2012) suggests that the effect of M. elsdenii differs by diet composition. Lower concentrations of NEFA and higher molar proportions of propionate in M. elsdenii-dosed cows versus control cows may indicate less lipolysis and a decreased risk of ketosis in fresh cows with M. elsdenii inoculation, but more research is needed since there was no treatment difference in plasma BHB concentrations (Zebeli et al., 2012). 


\section{G. Hypotheses}

Based on the results of in vitro studies with Megasphaera elsdenii, there is promise for improved performance in dairy cows during high-stress transition periods; however, none of the present in vivo studies have shown a significant difference in performance between treatments. We hypothesized that administering M. elsdenii would improve milk yield and decrease the incidence of metabolic disease in early lactation dairy cows. In addition, we also hypothesized that administering $M$. elsdenii both prepartum and at calving, compared to previous studies in which M. elsdenii was only administered postpartum, would improve performance and health further than either a single-dose prepartum or postpartum. 


\section{CHAPTER 3: MATERIALS AND METHODS}

\section{Experimental Design, Treatments, and Diets}

Primi- and multiparous Holstein cows $(n=162)$ at the Miedema Dairy Farm (Circleville, $\mathrm{OH}$ ) were enrolled in the trial beginning August 22, 2012. Dry cows and heifers were placed on the trial at $\sim 14 \mathrm{~d}$ prepartum until the last cow calved on November 11, 2012. The trial ended on February 8, 2013 when the last cow reached 90 DIM. Cows were followed until 90 DIM for milk production and health data and until 150 DIM for reproduction data. The study was conducted as a randomized complete block design. Cows and heifers were blocked based on expected calving date and parity. The researchers chose to use a commercial farm rather than a university farm in order to have higher animal numbers and potential for increased metabolic disease prevalence.

Within each block cows were randomly assigned to 1 of 4 treatments: 1) control (no dose) (n=44), 2) 200 mL Lactipro (M. elsdenii, $1 \times 10^{8}$ cfu/mL; MSBiotec, Littleton, CO) when cows entered ( -14 DIM) the close-up pen $(n=45), 3) 200 \mathrm{~mL}$ Lactipro at 1-3 d postpartum ( $\mathrm{n=39})$, and 4) $200 \mathrm{~mL}$ Lactipro prepartum and another $200 \mathrm{~mL}$ at 1-3 d postpartum $(\mathrm{n}=34)$. The $200 \mathrm{~mL}$ doses of Lactipro were administered orally while cows were in headlocks during the morning feeding. The researchers chose not to have a placebo dose in order to more closely mimic actual on-farm use of the Lactipro product. The different number of animals per treatment was due to early removal of some animals 
by the farm manager and failure of animals to be dosed postpartum. Cows were housed in 1 of 2 dry cow groups prepartum in a 4-row freestall barn and were moved, within the same facility, into a fresh cow group postpartum. All cows had ad libitum access to a TMR, which was mixed and delivered every day at $0900 \mathrm{~h}$. Close-up cows were fed a diet formulated with $72 \%$ forage (63:37 corn silage and wheat straw), and upon calving, cows entered the high group with a diet formulated for $40 \%$ forage (90:10 corn silage and wheat straw). Ingredient compositions for both the dry and high cow TMR are listed in Table 1. All cows had ad libitum access to water.

\section{BCS and Weight}

Cows were body condition scored ( 1 to 5 on a quarter unit scale; $1=$ thin, $5=$ fat) prepartum ( -14 DIM) and at 30,60, and 90 DIM. The principal investigator did the majority of the body condition scoring with the assistance of 2 other research personnel that were trained by the principal investigator. The BW was estimated concurrently with the second blood collection day (7 to 14 DIM) via weigh tape (Coburn Co., Whitewater, WI).

\section{Urine and Blood Metabolites}

In order to determine the metabolic status of the cows pre- and postpartum, blood samples were collected from the median coccygeal vein or artery 3 to $5 \mathrm{~d}$ prior to the expected calving date and again at 7 to 14 DIM for analysis of BHBA and NEFA. The blood samples were collected in $10 \mathrm{~mL}$ Vacutainer serum collection tubes (BD 
Vacutainer, Franklin Lakes, NJ). Blood tubes were immediately placed on ice until they were centrifuged at $2000 \times \mathrm{g}$ at $4{ }^{\circ} \mathrm{C}$ for $20 \mathrm{~min}$. The serum was then decanted and divided between 2 plastic disposable culture tubes. Serum samples were frozen at $-20{ }^{\circ} \mathrm{C}$ until analysis. The NEFA concentrations were determined using an enzymatic colorimetric method assay (Wako Diagnostics, Richmond, VA). The BHBA concentrations were analyzed using an enzymatic assay kit (Sigma-Aldrich Co. LLC, St Louis, MO). All samples were analyzed in duplicate for both NEFA and BHBA assays. The concentration of BHBA and NEFA were calculated using the absorbance values obtained from the microplate spectrophotometer (Molecular Devices Corp., Sunnyvale, CA). Urine ketones (acetoacetate) were measured at 7 to 14 DIM using Ketostix (Bayer Corporation, Leverkusen, Germany) for comparison with blood BHBA and milk fat percentage.

\section{Health and Reproduction Events}

Reproduction and health events were monitored until 150 and 90 DIM, respectively. Dairy personnel recorded all reproduction and health events in DairyCOMP 305 (Valley Agricultural Software, Tulare, CA).

\section{Feed Sampling and Analyses}

Each week, a sample of the dry cow TMR, the high cow TMR, and individual dietary components were collected and frozen at $-20^{\circ} \mathrm{C}$ for later nutrient analysis. The weekly TMR samples for each diet were dried at $55^{\circ} \mathrm{C}$ for $48 \mathrm{~h}$ and ground through a 1- 
mm screen (Wiley Mill, Arthur H. Thomas Co., Philadelphia, PA). Weekly TMR samples were analyzed for DM (AOAC, 1990), crude protein ( $\mathrm{N}$ x 6.25) (AOAC, 1990; Kjeldahl N, Foss 220 Kjeltec Auto Distillation, Eden Praire, MN), and ash (AOAC, 1990). The NDF content of the TMR samples was analyzed using an ANKOM 200 fiber analyzer (Ankom Technology, Macedon, NY) based on procedures of Van Soest et al. (1991) using heat-stable $\alpha$-amylase and sodium sulfite. The weekly TMR samples were composited by month for mineral and fat analyses. Mineral concentrations of the composited TMR samples were analyzed using inductively coupled plasma emission spectrometry by The Ohio State University STAR laboratory (Wooster, OH). Composite TMR samples were analyzed for fat content by ether extraction (AOAC, 2006) at Cumberland Valley Analytical Services (Maugansville, MD).

\section{Milk Collection and Analyses}

Cows were milked 3 times daily $(0500,1300$, and $2100 \mathrm{~h})$ and daily milk yield was recorded until 90 DIM using Afimilk (Kibbutz Afikim, Israel) and DairyCOMP 305 (Valley Agricultural Software, Tulare, CA) data collection. Daily milk yield was averaged weekly for each cow for milk production analysis. Peak milk and week of peak milk were calculated from the weekly milk yield averages. Milk composition data were collected from the monthly DHI (DHI Cooperative, Inc., Columbus, OH) samples taken from the first daily milking during the first two test dates postpartum. The DHI composition analyses of milk fat and protein were determined by infrared spectroscopy (B2000 Infrared Analyzer, Bentley Instruments, Chaska, MN), and SCC were analyzed using a Bentley Somacount 300 (Bentley Instruments, Chaska, MN). 


\section{Statistical Analysis}

Data were analyzed using PROC MIXED of SAS (SAS Institute, 2004) as a randomized complete block design with treatment, time, and parity as fixed effects and block as the random effect. Milk yield, milk fat and protein percentages, SCC, projected 305 d milk production, and BCS were analyzed as repeated measures. An autoregressive order 1 covariate matrix was used. Prepartum BCS was used for covariate adjustment of BCS data. The PDIFF option in the LSMEANS statement was used to separate means. Significant differences were declared at $P \leq 0.05$ and trends at $P \leq 0.10$. Nonsignificant 2- and 3-way interactions were pooled into the error term. 


\section{CHAPTER 4: RESULTS}

\section{Experimental Design, Animals, and Treatments}

Cows in the prepartum only and pre- and postpartum treatments were dosed, on average, $8 \mathrm{~d}$ prior to calving, which varied slightly from the intended dosing time of $14 \mathrm{~d}$ prepartum. Cows were not included in data analysis if they were culled from the herd or died before the 7 to14 DIM measurements could be collected. In addition, entire blocks were deleted if they contained fewer than 2 cows. The postpartum only and pre- and postpartum treatments contained the fewest number of cows, 39 and 34 cows respectively, while the control and prepartum only treatment contained 44 and 45 cows respectively.

\section{Feed Composition}

Chemical composition of the 2 diets is shown in Table 2. Differences between the formulated and actual nutrient content of the diets occurred. Variability between the calculated and analyzed CP and NDF concentrations for the dry cow TMR did exist. On a DM basis, the analyzed CP for the dry cow diet was $14 \%$ lower than the calculated and the analyzed NDF value was $9 \%$ higher than the calculated value. Differences between the calculated and analyzed dry cow TMR were observed for $\mathrm{K}, \mathrm{Ca}, \mathrm{Mg}, \mathrm{S}, \mathrm{Cu}$, and $\mathrm{Mn}$, of which $\mathrm{Cu}$ was the only one in which the analyzed amount was greater. The minerals with the most variability in the high cow TMR were $\mathrm{K}, \mathrm{P}, \mathrm{Mg}, \mathrm{S}, \mathrm{Cu}, \mathrm{Mn}$, and 
$\mathrm{Zn}$, of which $\mathrm{K}$ and Mn were the only 2 in which the analyzed amount was less than the calculated. Overall, dietary concentrations of nutrients in the actual diets met or exceeded NRC (2001) recommendations.

\section{BCS and Weight}

The BCS did not differ by treatment (Table 3), but it differed by DIM (Figure 1). No difference in BCS occurred between 30 and 60 DIM, but there was a difference for both 30 and 60 DIM to be lower compared to 90 DIM. The higher BCS at 90 DIM suggests the cows were regaining the body condition they had lost postpartum. There was no treatment by day interaction for BCS $(P>0.10)$. Postpartum BW measured between 7 and 14 DIM did differ by treatment. Cows dosed pre- and postpartum had higher $(P<$ 0.05) BW than either of the prepartum or postpartum dosing treatments. The control cows also had a higher $(P<0.05) \mathrm{BW}$ than the prepartum dosed cows.

\section{Milk Production and Composition}

Milk production and composition data are provided in Table 3. Daily milk yield did not differ by treatment, with cows producing an average of $39.7 \mathrm{~kg} / \mathrm{d}$. As expected, a week difference by DIM was observed for daily milk yield $(P<0.01)$ (Figure 2);

however, there was no treatment by week interaction for daily milk yield $(P>0.10)$.

Projected 305 d milk yield did not differ by treatment and test-day, and no treatment by test-day interaction was observed. Peak milk yield did not differ by treatment, and cows across all treatments peaked at an average of $45.6 \mathrm{~kg} / \mathrm{d}$. Treatment by parity interactions 
$(P<0.05)$ occurred for daily milk yield (Figure 3 ) and for peak milk (Figure 4) and differences among treatments were most pronounced for cows with $\geq 3$ lactations. The mature cows dosed prepartum had higher daily milk yield and peak milk than the control and pre- and postpartum dosed cows but did not differ from the postpartum dosed cows. Week of peak milk did not differ by treatment and occurred between 8 and 9 wk in lactation.

Milk fat percentage did not differ by treatment, and milk fat percentage averaged 3.63\% across all treatments. As expected, the first test-day milk fat percentage was higher $(P<0.01)$ than the second test-day, $3.88 \%$ and $3.38 \%$, respectively. The average milk protein percentage across all treatments was $3.08 \%$ and did not differ by treatment. Milk protein percentage was higher $(P<0.01)$ on the first test-day than the second test-day ( $3.16 \%$ and $2.99 \%$, respectively). There was no interaction of treatment by time for milk fat or protein percentages $(P>0.10)$, but a treatment by parity interaction $(P<0.01)$ occurred for milk protein (Figure 5). Milk protein percentage was higher for $2^{\text {nd }}$ lactation cows dosed prepartum than control or cows dosed pre- and postpartum but did not differ from cows dosed postpartum. Control and pre- and postpartum dosed cows with $\geq 3$ lactations had higher milk protein percentages than those dosed only prepartum but were not different from cows dosed only postpartum. The SCC did not differ by treatment or DHI test-day and averaged $333\left(\mathrm{x} 10^{3}\right)$ cells $/ \mathrm{ml}$ across all treatments. A treatment by DHI test-day interaction occurred $(P=0.05)$, but this was mainly the result of 3 postpartum dosed cows having SCC between 2,000,000 and $5,000,000$ cells/ml. 


\section{Urine and Blood Metabolites}

The results for urine and blood metabolites are listed in Table 3. Urine ketones (acetoacetate) did not differ among treatments. Prepartum blood was collected, on average, $6 \mathrm{~d}$ prior to calving which varied slightly from the intended sampling time of 3 to $5 \mathrm{~d}$ prepartum. Neither the prepartum nor postpartum NEFA concentrations differed for cows dosed with $M$. elsdenii or control cows. The prepartum and postpartum BHBA concentrations also did not differ among treatments.

\section{Reproduction and Health}

All reproduction and health events are shown in Table 4. The incidence of monitored health events did not differ among treatments, and as expected, the 2 most prevalent health events were mastitis and lameness. A new episode of mastitis was defined as an episode occurring $14 \mathrm{~d}$ after the treatment of a previous episode as described by Adkinson et al. (1993). The farm personnel did not record any incidences of ketosis, SARA, or displaced abomasum for cows during the trial.

The DIM at $1^{\text {st }}$ service did not differ by treatment, and on average, cows were first serviced at 74 DIM across all treatments. There was no difference in the number of cows pregnant by 150 DIM and approximately $68 \%$ of the cows in each treatment were confirmed pregnant by this stage of lactation. Of the confirmed pregnant cows by 150 DIM, it took an average of 1.65 services per conception, and there was no difference among treatments for the number of services per conception. 


\section{CHAPTER 5: DISCUSSION}

\section{BCS and Weight}

The suggested BCS score at calving for optimal milk production is 3.5 , but little difference in milk production exists between a BCS of 3.0 and 3.5 (Roche et al., 2009). In addition, cows should not lose more than 0.5 to 1.0 units postpartum (Roche et al., 2009). The cows on our study had a BCS of 3.24 in the 2 wk prior to calving and only lost 0.3 units between the 2 wk prepartum and 30 DIM. Thus, the BCS of cows in our study conformed to industry recommendations for maximum milk production. Similar to our study, Hagg et al. (2010) did not observe a difference in BCS between M. elsdenii-dosed and control cows. Conversely, Henning et al. (2011) reported that cows dosed with $M$. elsdenii tended to have higher BCS than control cows. The treatment difference in BW observed in our study is not likely due to a true treatment difference, as cows were not blocked by BW, a covariate for BW was not included in the analysis, and the measurement of BW was by heart girth tape. The effect of dosing $M$. elsdenii on BW is inconsistent in the existing literature. Aikman et al. (2009) reported no treatment difference in BW for dosed or control cows, but cows dosed with M. elsdenii tended to either lose less or gain more weight than control cows. In contrast, in a study by Henning et al. (2011), cows dosed with $M$. elsdenii had higher BW than control cows. In addition, the difference in BW and BCS was accentuated in high-producing cows on a higher 
energy diet (70\% concentrate). It may be beneficial for future studies to evaluate changes in $\mathrm{BW}$, in addition to $\mathrm{BCS}$, when assessing the effect of dosing M. elsdenii to cows in early lactation.

\section{Milk Production and Composition}

Administration of M. elsdenii had little effect on milk yield or milk composition in this study. Similarly, other studies (Aikman et al., 2009; Hagg et al., 2010; Aikman et al., 2011) also have revealed no difference in milk yield when cows were dosed immediately postpartum. Henning et al. (2011) observed a trend for higher milk yield by cows dosed with M. elsdenii on 10 and 20 DIM compared to control cows. In our study, there was a treatment by parity interaction for milk yield and peak milk in which mature cows ( $\geq 3$ lactations) dosed prepartum produced more milk and peaked higher than control cows and cows dosed with M. elsdenii both pre- and postpartum. The lack of a response in milk production may be contributed to the composition of the lactating cow diet and good herd management. The 59\% concentrate in the lactating cow diet in our study is comparable to the low concentrate diets (60\% concentrate) fed by Hagg et al. (2010) and Henning et al. (2011). Because neither of these studies observed a difference in control and M. elsdenii-dosed cows for milk yield suggests that cows on a lower concentrate (low NSC) diet did not benefit as much from M. elsdenii administration compared to those fed the higher NSC diet. In addition, proper feeding management, such as uniform feed mixing, no empty bunks, and optimal fiber length also may minimize potential differences between control and M. elsdenii dosed cows. 
The milk fat percentage did not differ between cows dosed with $M$. elsdenii and control cows, which is in agreement with the studies by Aikman et al. (2009) and Zebeli et al. (2012). Conversely, Aikman et al. (2011) observed a trend for milk fat concentration to be reduced in cows dosed with M. elsdenii. Although Hagg et al. (2010) did not observe an overall treatment difference between control cows and cows dosed with $M$. elsdenii, there was a significant difference in milk fat percentage between dosed and control cows fed a high concentrate diet ( $70 \%$ concentrate). The milk fat percentages in our study are consistent with the national average of $3.7 \%$ for Holstein cows and do not indicate there was a high risk for SARA. However, it must be noted that cows in our study were in early lactation and higher milk fat percentages are expected due to the mobilization of adipose tissue. In addition, the lack of a milk fat depression with the administration of $M$. elsdenii suggests that this strain may not be associated with the production of trans-10,cis-12 conjugated linoleic acid, unlike some of the M. elsdenii strains studied by others (Kim et al., 2002; Palmonari et al., 2010; Weimer et al., 2010). The suggestion that M. elsdenii produces trans-10,cis-12 conjugated linoleic acid is refuted by Maia et al. (2007) and Wallace et al. (2007). Neither of the 2 M. elsdenii strains in the Maia et al. (2002) study were found to produce trans-10,cis-12 conjugated linoleic acid. Of the M. elsdenii strains studied by Wallace et al. (2007), including the strain used by Kim et al. (2002), none of the M. elsdenii produced trans-10,cis-12 conjugated linoleic acid.

Similar to our observation of no difference in milk protein percentage between control and M. elsdenii-dosed cows, none of the other dairy cattle studies that evaluated milk protein observed a difference between control and dosed cows. The treatment by 
parity interaction observed in our trial is likely due to a dilution effect, as similar trends were observed for milk yield and peak milk. In contrary to our study, where there was no observed difference in SCC for control or dosed cows, Zebeli et al. (2012) reported a trend for M. elsdenii dosed cows to have higher SCC than control cows. The authors did note that both the control and dosed cattle had SCC below 150,000 cells/ml. In agreement with Hagg et al. (2010), there was no difference in the 305-d predicted milk between cows dosed with $M$. elsdenii and control cows. Overall, the administration of M. elsdenii, regardless of dosing day relative to calving, had little effect on milk yield and composition in this study. However, the treatment by parity interaction may suggest higher producing cows with higher DMI may benefit from dosing with M. elsdenii.

\section{Urine and Blood Metabolites}

Urine ketones and plasma NEFA and BHBA are commonly used as indicators of energy status in early lactation dairy cattle. The concentration of urine ketones in our study suggests the incidence of ketosis in our study was low across all treatments. Carrier et al. (2004) suggested $15 \mathrm{mg} / \mathrm{dl}$ as the cutoff point for subclinical ketosis when using Ketostix to measure urine ketones. Based on this cutoff point, only $2.5 \%$ of all cows in the study experienced clinical ketosis, and cows with $\geq 15 \mathrm{mg} / \mathrm{dL}$ were $8.33,14.3,14.3$, and $0 \%$ for treatments, respectively. The prepartum and postpartum NEFA and BHBA concentrations also suggest that cows on our trial did not suffer from severe NEB. The NEFA concentrations in this study did not exceed the thresholds of $\geq 0.3 \mathrm{mEq} / \mathrm{L}$ and $\geq$ $0.6 \mathrm{mEq} / \mathrm{L}$ for prepartum and postpartum, respectively (Ospina et al., 2010). The BHBA 
concentrations in our study did not exceed the threshold of 1,200 to $1,400 \mu \mathrm{mol} / \mathrm{L}(12.4$ to $14.4 \mathrm{mg} / \mathrm{dl}$ ) for postpartum cows (Duffield et al., 2009; Suthar et al., 2013).

Although not significant, the prepartum and postpartum dosing treatments had the highest prepartum and postpartum NEFA, which corresponds to the higher milk production for these 2 treatments for the mature cows because higher producing cows have a higher energy demand. Zebeli et al. (2012) measured preprandial NEFA and BHBA and found no difference between $M$. elsdenii-dosed cows and control cows. However, there was a significant postprandial effect in which control cows had higher plasma NEFA than dosed cows. The low urine ketones and NEFA and BHBA concentrations in our study are in agreement with the absence of any reported cases of ketosis. In addition, an elevated milk fat percentage of one standard deviation above the average, about 1 percentage unit, is suggestive of ketosis in early lactation dairy cows (Eastridge, 2012). Based on this, the cows in our study had low prevalence of ketosis; the average milk fat percentage for all cows in the first 30 DIM was only $4.15 \%$, and the average for the first 90 DIM was 3.63\%. The effect of dosing with M. elsdenii on urine ketones and plasma NEFA and BHBA remains unclear but may indicate improved energy status.

\section{Reproduction and Health}

Evidence that dosing cows with M. elsdenii NCIMB 41125 reduces the incidence of health events is inconsistent. In the study by Leeuw et al. (2009), dosing M. elsdenii NCIMB 41125 to feedlot steers on low roughage diets reduced the incidences of bloat and diarrhea. The number of animals treated for illnesses also was numerically less for 
the steers dosed than control (15 and 26, respectively). Of the cows culled for a decline in milk production, DMI, or illness in the lactating cow study by Hagg et al. (2010), fewer cows were culled from the M. elsdenii treatments than the control treatment. Four and 7 cows from the low and high control treatments, respectively, and 1 from each of the low and high dosed treatments were culled. In our study, dosing early lactation cows with $M$. elsdenii did not appear to reduce the occurrence of health problems. The herd personnel reported no incidences of SARA, ketosis, or displaced abomasum. The absence of the incidence of SARA in this study may suggest that the lactating diet did not have sufficient NFC to cause a rumen challenge and thus mitigated any possible effect of dosing with M. elsdenii.

Reproduction success in dairy cattle can be linked to nutrition and health status; thus, the NEB that cows experience in the first few weeks of lactation could adversely affect reproductive performance. Domecq et al. (1997) reported that cows were 1.17 and 1.36 times less likely to conceive if cows lost 0.4 or 0.8 BCS units, respectively, in the first months after calving compared to those cows that did not change in BCS. The services per conception in our study were positively below the recommended benchmark of 2.5. The low number of services per conception in our study indicates that cows may not have experienced a NEB severe enough to adversely affect reproduction. The suggested goal for DIM at $1^{\text {st }}$ service is 50 to $70 \mathrm{~d}$, and the cows in our trial were slightly past this goal (average of 74 DIM). The DIM at $1^{\text {st }}$ service observed in our study is likely due to farm-specific reproduction protocols because there were low incidences of health events. 


\section{Implications}

As food-animal production industries move away from antibiotic use and towards other animal health practices, such as DFM, it is important to understand the effects that DFM have on milk production, milk composition, and animal health. From this study and others investigating the effect of $M$. elsdenii administration in dairy cattle fed typical transition diets, M. elsdenii does not appear to increase the milk yield of early lactation cows or reduces health events. However, dosing with $M$. esldenii either 2-wk prepartum or 1 to $3 \mathrm{~d}$ postpartum increased the milk production of the higher producing mature cows ( $\geq 3$ lactations). The administration of $M$. elsdenii both prepartum and immediately following calving did not further improve cow performance and suggests that only one dose of M. elsdenii prepartum is potentially valuable. Future studies should evaluate the effect of dosing both prepartum and postpartum with cows fed a diet with higher concentrations of starch or NFC either prepartum or postpartum.

\section{Conclusions}

The milk yield and composition were similar among treatments. Dosing with $M$. elsdenii prepartum may improve ruminal conditions of high-producing (higher parity) transition cows whereby milk yield is increased. Although administration of M. elsdenii did not appear to affect overall cow performance, concentrations of dietary starch and NDF fed both prepartum and postpartum may affect animal response to dosing with $M$. elsdenii. 


\section{REFERENCES}

Adkinson, R.W., K.H. Ingawa, D.C. Blouin, and S.C. Nickerson. 1993. Distribution of clinical mastitis among quarters of the bovine udder. J. Dairy Sci. 76:3453-3459.

Aikman, P.C., P.H. Henning, C.H. Horn, and A.K. Jones. 2009. Effect of using Megasphaera elsdenii NCIMB 41125 as a probiotic on feed intake and milk production in early lactation dairy cows. In: Ruminant Physiology - Digestion, metabolism and effects of nutrition on reproduction and welfare. Eds. Y.Chilliard, F.Glasser, Y.Faulconnier, F. Bocquier, I. Veissier \& M. Doreau. Wageningen Academic Publishers. p 110-111.

Aikman, P. C., P. H. Henning, D. J. Humphries, and C. H. Horn. 2011. Rumen pH and fermentation characteristics in dairy cows supplemented with Megasphaera elsdenii NCIMB 41125 in early lactation. J. Dairy Sci. 94:2840-2849.

Allen, M. S. 1996. Physical constraints on voluntary intake of forages by ruminants. J. Anim. Sci. 74:3063-3075.

Allen, M. S. 1997. Relationship between fermentation acid production in the rumen and the requirement for physically effective fiber. J. Dairy Sci. 80:1447-1462.

Allen, M. S., B. J. Bradford, and M. Oba. 2009. Board-invited review: The hepatic oxidation theory of the control of feed intake and its application to ruminants. J. Anim. Sci. 87:3317-3334.

Asanuma, N., and T. Hino. 2005. Ability to utilize lactate and related enzymes of a ruminal bacterium, Selenomonas ruminantium. Anim. Sci. J. 76:345-352.

Asanuma, N., M. Iwamoto, and T. Hino. 1997. Regulation of lactate dehydrogenase synthesis in a ruminal bacterium, Streptococcus bovis. J. Gen. Appl. Microbiol. 43:325331.

AOAC. 1990. Official Methods of Analysis. Vol. I. 15 ${ }^{\text {th }}$ ed. Association of Official Analytical Chemists, Arlington, VA.

AOAC. 2006. Official Methods of Analysis. $18^{\text {th }}$ ed. Association of Official Analytical Chemists, Gaithersburg, MD. 
Beauchemin, K.A., L.M. Rode, W.Z. Yang, and C.J. Newbold. 2000. Enzymes and direct fed microbials in diets for dairy cows. Proceedings Tri-State Dairy Nutrition Conference. M.L. Eastridge ed. The Ohio State University, Columbus. p. 85-94.

Beauchemin, K. A., W. Z. Yang, and L. M. Rode. 2003. Effects of particle size of alfalfabased dairy cow diets on chewing activity, ruminal fermentation, and milk production. $\mathrm{J}$. Dairy Sci. 86:630-643.

Bond, D. R., and J. B. Russell. 1996. A role for fructose 1,6-diphosphate in the ATPasemediated energy-spilling reaction of Streptococcus bovis. Appl. Environ. Microbiol. 62:2095-2099.

Brown, M., and T.G. Nagaraja. 2009. Direct-fed microbials for growing and finishing cattle. In Plains Nutrition Council Spring Conference Publication. No. AREC 09-10, 4260. Amarillo: Texas A\&M Research and Extension Center.

Bruno, R.G.S., H.M. Rutigliano, R.L. Cerri, P.H. Robinson, J.E.P. Santos. 2009. Effect of feeding Saccharomyces Cerevisiae on performance of dairy cows during summer heat stress. Anim. Feed Sci. Technol. 150:175-186.

Butler, W. R., and R. D. Smith. 1989. Interrelationships between energy balance and postpartum reproductive function in dairy cattle. J. Dairy Sci. 72:767-783.

Carrier, J., S. Stewart, S. Godden, J. Fetrow, and P. Rapnicki. 2004. Evaluation and use of three cowside tests for detection of subclinical ketosis in early postpartum cows. J. Dairy Sci. 87:3725-3735.

Chow, J. M., and J. B. Russell. 1990. Effect of ionophores and pH on growth of Streptococcus bovis in batch and continuous culture. Appl. Environ. Microbiol. 56:15881593.

Collier, R. J., D. K. Beede, W. W. Thatcher, L. A. Israel, and C. J. Wilcox. 1982.

Influences of environment and its modification on dairy animal health and production. J. Dairy Sci. 65:2213-2227.

Counotte, G. H. M., A. Lankhorst, and R. A. Prins. 1983. Role of DL-lactic acid as an intermediate in rumen metabolism in dairy cows. J. Anim. Sci. 56:1222-1235.

Counotte, G. H. M., R.A. Prins, R. H. A. M. Janssen, and M. J. A. DeBie. 1981. Role of Measphaera elsdenii in the fermentation of DL- $\left[2-{ }^{13} \mathrm{C}\right]$ lactate in the rumen of dairy cattle. Appl. Environ. Microbiol. 42:649-655.

Dennis, S. M., and T. G. Nagaraja. 1981. Effect of lasalocid or monensin on lactateproducing or using rumen bacteria. J. Anim. Sci. 52:418-426. 
Dijkstra, J., H. Boer, J. Van Bruchem, M. Bruining, and S. Tamminga. 1993. Absorption of volatile fatty acids from the rumen of lactating dairy cows as influenced by volatile fatty acid concentration, $\mathrm{pH}$ and rumen liquid volume. British J. of Nutr. 69:385-396.

Domecq, J.J., A.L. Skidmore, J.W. Lloyd, and J.B. Kaneene. 1997. Relationship between body condition scores and conception at first artificial insemination in a large dairy herd of high yielding Holstein cows. J. Dairy Sci. 80:113-120.

Drouillard, J. S., P. H. Henning, H. H. Meissner, and K-J. Leeuw. 2012. Megasphaera elsdenii on the performance of steers adapting to a high-concentrate diet, using three or five transition diets. S. Afr. J. Anim. Sci. 42:195-199.

Duffield, T. F., K. D. Lissemore, B. W. McBride, and K. E. Leslie. 2009. Impact of hyperketonemia in early lactation dairy cows on health and production. J. Dairy Sci. 92:571-580.

Eastridge, M.L. 2012. Variation in milk fat of fresh cows. Proceedings Tri-State Dairy Nutrition Conference. M.L. Eastridge ed. The Ohio State University, Columbus. p. 59-65.

Enemark, J. M. D. 2009. The monitoring, prevention and treatment of sub-acute ruminal acidosis (SARA): A review. Vet. J. 176:32-43.

Erdman, R. A. 1988. Dietary buffering requirements of the lactating dairy cow: A review. J. Dairy Sci. 71:3246-3266.

Fernando, S. C., H. T. Purvis II, F. Z. Najar, L. O. Sukharnikov, C. R. Krehbiel, T. G. Nagaraja, B. A. Roe, and U. DeSilva. 2010. Rumen microbial population dynamics during adapatation to a high-grain diet. Appl. Environ. Microbiol. 76:7482-7490.

Firkins, J. L., M. L. Eastridge, N. R. St-Pierre, and S. M. Noftsger. 2001. Effects of grain variability and processing on starch utilization by lactating dairy cattle. J. Anim. Sci. 79(E. Suppl.):E218-E238.

Forsberg, C. W. 1978. Nutritional characteristics of Megasphaera elsdenii. Can. J. Microbiol. 24:981-985.

Friend, T. H., C. E. Polan, and M. L. McGilliard. 1977. Free stall and feed bunk requirements relative to behavior, production and individual feed intake in dairy cows. J. Dairy Sci. 60:108-116.

Ghorbani, G.R., D. P. Morgavi, K. A. Beauchemin, and J. A. Z. Leedle. 2002. Effects of bacterial direct-fed microbials on ruminal fermentation, blood variables, and the microbial populations of feedlot cattle. J. Anim. Sci. 80:1977-1985. 
Goad, D.W., C.L. Goad, and T.G. Nagaraja. 1998. Ruminal microbial and fermentative changes associated with experimentally induced subacute acidosis in steers. J. Anim. Sci. 76:234-241.

Grant, R. J., and J. L. Albright. 1995. Feeding behavior and management factors during the transition period in dairy cattle. J. Anim. Sci. 73:2791-2803.

Grant, R. J., and J. L. Albright. 2001. Effect of animal grouping on feeding behavior and intake of dairy cattle. J. Dairy Sci. 84(E. Suppl.):E156-E163.

Gressley, T. F., M. B. Hall, and L. E. Armentano. 2011. Ruminant nutrition symposium: Productivity, digestion, and health responses to hindgut acidosis in ruminants. J. Anim. Sci. 89:1120-1130.

Grummer, R. R. 1995. Impact of changes in organic nutrient metabolism on feeding the transition dairy cow. J. Anim. Sci. 73:2820-2833.

Hagg, F. M., L. J. Erasmus, P. H. Henning, and R. J. Coertze. 2010. The effect of a direct fed microbial (Megasphaera elsdenii) on the productivity and health of Holstein cows. S. Afr. J. Anim. Sci. 40:101-112.

Henning, P. H., L. J. Erasmus, H. H. Meissner, and C. H. Horn. 2011. The effect of dosing Megasphaera elsdenii NCIMB 41125 (Me) on lactation performance of multiparous Holstein cows. S. Afr. J. Anim. Sci. 41:156-160.

Henning, P.H., C.H. Horn, K.-J. Leeuw, H.H. Meissner, and F.M. Hagg. 2010a. Effect of ruminal administration of the lactate- utilizing strain of Megasphaera elsdenii (Me) NCIMB 41125 on abrupt or gradual transition from forage to concentrate diets. Anim. Feed Sci. Technol. 157:20-29.

Henning, P. H., C. H. Horn, D. G. Steyn, H. H. Meissner, and F. M. Hagg. 2010b. The potential of Megasphaera elsdenii isolates to control ruminal acidosis. Anim. Feed Sci. and Technol. 157:13-19.

Hiltner, P., and B. A. Dehority. 1983. Effect of soluble carbohydrates on digestion of cellulose by pure cultures of rumen bacteria. Appl. Environ. Microbiol. 46:642-648.

Hino, T., and S. Kuroda. 1993. Presence of lactate dehydrogenase and lactate racemase in Megasphaera elsdenii grown on glucose or lactate. Appl. Environ. Microbiol. 59:255259.

Hino, T., K. Shimada, and T. Maruyama. 1994. Substrate preference in a strain of Megasphaera elsdenii, a ruminal bacterium, and its implications in proprionate production and growth competition. Appl. Environ. Microbiol. 60:1827-1831. 
Horn, C. H., A. Kistner, and G. Fouché. 2009. Selective enrichment, isolation and characterization of fast-growing acid-tolerant and ionophores-resistant lactate utilisers from rumen contents of animals on high-energy diets. In: Ruminant Physiology Digestion, Metabolism and Effects of Nutrition on Reproduction and Welfare. Eds. Chilliard, Y., Glasser, F., Faulconnier, Y., Bocquier, F., Veissier, I., and Doreau, M., Wageningen Academic Publishers. p 216-217.

Hutjens, M. F. 1996. Practical approaches to feeding the high producing cow. Anim. Feed Sci. Technol. 59:199-206.

Ipharraguerre, I. R., and J. H. Clark. 2003. Usefulness of ionophores for lactating dairy cows: A review. Anim. Feed Sci. Technol. 106:39-57.

Jorritsma, R., T. Wensing, T. A. M. Kruip, P. L. A. M. Vos, and J. P. T. M. Noordhuizen. 2003. Metabolic changes in early lactation and impaired reproductive performance in dairy cows. Vet. Res. 34:11-26.

Kammes, K. L. and M. S. Allen. 2012. Rates of particle size reduction and passage are faster for legume compared with cool-season grass, resulting in lower rumen fill and less effective fiber. J. Dairy Sci. 95:3288-3297.

Kim, Y.J., R.H. Liu, J.L. Rychlik and J.B. Russell. 2002. The enrichment of a ruminal bacterium (Megasphaera elsdenii YJ-4) that produces the trans-10, cis-12 isomer of conjugated linoleic acid. J. Appl. Microbiol. 92:976-982.

Kleen, J.L., G.A. Hooijer, J. Rehage, and J.P.T.M. Noordhuizen. 2003. Subacute ruminal acidosis (SARA): A review. J. Vet. Med. 50:406-414.

Klieve, A. V., D. Hennessy, D. Ouwerkerk, R. J. Forster, R. I. Mackie, and G. T. Attwood. 2003. Establishing populations of Megasphaera elsdenii YE 34 and Butyrivibrio fibrisolvens YE 44 in the rumen of cattle fed high grain diets. J. Appl. Microbiol. 95:621-630.

Krause, K. M., and G. R. Oetzel. 2006. Understanding and preventing subacute ruminal acidosis in dairy herds: A review. Anim. Feed Sci. Tech. 126:215-236.

Krehbiel, C.R., S. R. Rust, G. Zhang, and S. E. Gilliland. 2003. Bacterial direct-fed microbials in ruminant diets: Performance response and mode of action. J. Anim. Sci. 81:E120-E132.

Kung, L., Jr. 1999. Direct-fed microbial and enzyme feed additives. In: S. Muirhead (ed.) 1998-1999 Direct-Fed Microbial, Enzyme and Forage Additive Compendium. Vol. 4. p 37. The Miller Publishing Co., Minnetoka, MN.

Kung, L. Jr., and A.O. Hession. 1995. Preventing in vitro lactate accumulation in ruminal fermentations by inoculation with Megasphaera elsdenii. J. Anim. Sci. 73:250-256. 
Leeuw, K-J., F.K. Siebrits, P.H. Henning, and H.H. Meissner. 2009. Effect of Megasphaera elsdenii NCIMB 41125 drenching on health and performance of steers fed high and low roughage diets in the feedlot. S. Afr. J. Anim. Sci. 39:337-348.

Lough, D. S., D. L. Beede, and C. J. Wilcox. 1990. Effects of feed intake and thermal stress on mammary blood flow and other physiological measurements in lactating dairy cows. J. Dairy Sci. 73:325-332.

Maia, M. R. G., L. C. Chaudhary, L. Figueres, and R. J. Wallace. 2007. Metabolism of polyunsaturated fatty acids and their toxicity to the microflora of the rumen. Antonie van Leeuwenhoek. 91:303-314.

Mallonée, P. G., D. K. Beede, R. J. Collier, and C. J. Wilcox. 1985. Production and physiological responses of dairy cows to varying dietary potassium during heat stress. J. Dairy Sci. 68:1479-1487.

Marounek, M., K. Fliegrova, and S. Bartos. 1989. Metabolism and some characteristics of ruminal strains of Megasohaera elsdenii. Appl. Environ. Microbiol. 55:1570-1573.

Martin, S.A., and D.J. Nisbet. 1992. Symposium: Direct-fed microbials and rumen fermentation. Effect of direct-fed microbials on rumen microbial fermentation. J. Dairy Sci. 75:1736-1744.

Mathew, B., M. L. Eastridge, E. R. Oelker, J. L. Firkins, and S. K. Karnati. 2011. Interactions of monensin with dietary fat and carbohydrate components on ruminal fermentation and production responses by dairy cows. J. Dairy Sci. 94:396-409.

McDaniel, M.R., J.M. Heidenreich, J.J. Higgins, and J.S. Drouillard. 2009. Investigations of the effect of Megasphaera elsdenii strain NCIMB 41125 on ruminal pH and ruminal concentrations of organic acids following a carbohydrate challenge. Cattlemen's Day 2009, Kansas State Univ., Manhattan. p. 62-65.

McGuire, M. A., D. K. Beede, M. A. DeLorenzo, C. J. Wilcox, G. B. Huntington, C. K. Reynolds, and R. J. Collier. 1989. Effects of thermal stress and level of feed intake on portal plasma flow and net fluxes of metabolites in lactating Holstein cows. J Anim. Sci. 67:1050-1060.

Mertens, D. R. 1997. Creating a system for meeting the fiber requirements of dairy cows. J. Dairy Sci. 80:1463-1481.

Meissner, H.H., P.H. Henning, C.H. Horn, K-J. Leeuw, F.M. Hagg, and G. Fouché. 2010. Ruminal acidosis: A review with detailed reference to the controlling agent Megasphaera elsdenii NCIMB 41125. S. Afr. J. Anim. Sci. 40:79-100. 
Mishra, M., F. A. Martz, R. W. Stanley, H. D. Johnson, J. R. Campbell, and E. Hilderbrand. 1970. Effect of diet and ambient temperature-humidity on ruminal $\mathrm{pH}$, oxidation reduction potential, ammonia and lactic acid in lactating cows. J. Anim. Sci. 30:1023-1028.

Mohammed, R., D. M. Stevenson , P. J. Weimer, G. B. Penner, and K. A. Beauchemin. 2012. Individual animal variability in ruminal bacterial communities and ruminal acidosis in primiparous Holstein cows during the periparturient period. J. Dairy Sci. 95:67166730.

Morgavi, D. P., M. Sakurada, M. Mizokami, Y. Tomita, and R. Onodera. 1994. Effects of ruminal protozoa on cellulose degradation and the growth of an anaerobic ruminal fungus, Piromyces sp. strain OTS1, in vitro. Appl. Environ. Microbiol. 60:3718-3723.

Mulligan, F. J., and M. L. Doherty. 2008. Production diseases of the transition cow. Vet. J. 176:3-9.

Mullins, C. R., L. K. Mamedova, M. J. Brouk, C. E. Moore, H. B. Green, K. L. Perfield, J. F. Smith, J. P. Harner, and B. J. Bradford. 2012. Effects of monensin on metabolic parameters, feeding behavior, and productivity of transition dairy cows. J. Dairy Sci. 95:1323-1336.

Mutsvangwa, T., J. P. Walton, J. C. Plaizier, T. F. Duffield, R. Bagg, P. Dick, G. Vessie, and B. W. McBride. 2002. Effects of a monensin controlled-release capsule or premix on attenuation of subacute ruminal acidosis in dairy cows. J. Dairy Sci. 85:3454-3461.

Nagaraja, T.G., and E.C. Titgemeyer. 2007. Ruminal acidosis in beef cattle: The current microbiological and nutritional outlook. J. Dairy Sci. 90(E. Suppl.): E17-E38.

National Research Council. 2001. Nutrient Requirements of Dairy Cattle. $7^{\text {th }}$ rev. ed. Natl. Acad. Sci., Washington, DC.

Newbold, C. J., A. G. Williams, and D. G. Chamberlain. 1987. The in-vitro metabolism of D,L-lactic acid by rumen microorganisms. J. Sci. Food Agric. 38:9-18.

Nocek, J. E. 1997. Bovine acidosis: Implications on laminitis. J. Dairy Sci. 80:10051028.

Nocek, J.E., W.P. Kautz, J.A.Z. Leedle, and E. Block. 2003. Direct-fed microbial supplementation on the performance of dairy cattle during the transition period. J. Dairy Sci. 86:331-335.

Oelker, E. R., C. Reveneau, and J. L. Firkins. 2009. Interaction of molasses and monensin in alfalfa hay- or corn silage-based diets on rumen fermentation, total tract digestibility, and milk production by Holstein cows. J. Dairy Sci. 92:270-285. 
Osborne, J. K., T. Mutsvangwa, O. Alzahal, T. F. Duffield, R. Bagg, P. Dick, G. Vessie, and B. W. McBride. 2004. Effects of monensin on ruminal forage degradability and total tract diet digestibility in lactating dairy cows during grain-induced subacute ruminal acidosis. J. Dairy Sci. 87:1840-1847.

Ospina, P.A., D. V. Nydam, T. Stokol, and T.R. Overton. 2010. Evaluation of nonesterified fatty acids and $\beta$-hydroxybutyrate in transition dairy cattle in the northeastern United States: Critical thresholds for prediction of clinical diseases. J. Dairy Sci. 93:546-554.

Overton, M. W., W. M. Sischo, G. D. Temple, and D. A. Moore. 2002. Using time-lapse video photography to assess dairy cattle lying behavior in a free-stall barn. J. Dairy Sci. 85:2407-2413.

Ouwerkerk, D., A.V. Klieve, and R.J. Forster. 2002. Enumeration of Megasphaera elsdenii in rumen contents by real-time Taq nuclease assay. J. Appl. Microbiol. 92:753758.

Owens, F. N., D. S. Secrist, W. J. Hill, and D. R. Gill. 1998. Acidosis in cattle: A review. J. Anim. Sci. 76:275-286.

Penner, G. B., M. A. Steele, J. R. Aschenbach, and B. W. McBride. 2011. Ruminant nutrition symposium: Molecular adaptation of ruminal epithelia to highly fermentable diets. J. Anim. Sci. 89:1108-1119.

Palmonari, A., D. M. Stevenson, D. R. Mertens, C. W. Cruywagen , and P. J. Weimer. 2010. $\mathrm{pH}$ dynamics and bacterial community composition in the rumen of lactating dairy cows. J. Dairy Sci. 93:279-287.

Penner, G. B., M. Taniguchi, L. L. Guan, K. A. Beauchemin, and M. Oba. 2009. Effect of dietary forage to concentrate ratio on volatile fatty acid absorption and the expression of genes related to volatile fatty acid absorption and metabolism in ruminal tissue. J. Dairy Sci. 92:2767-2781.

Plaizier, J.C., D.O. Krause, G.N. Gozho, B.W. McBride. 2009. Subacute ruminal acidosis in dairy cows: The physiological causes, incidence and consequences. Vet. J. 176:21-31.

Prabhu, R., E. Altman, and M.A. Eiteman. 2012. Lactate and acrylate metabolism by Megasphaera elsdenii under batch and steady-state conditions. Appl. Environ. Microbiol. 78:8564-8570.

Reveneau, C., S. K. R. Karnati , E. R. Oelker, and J. L. Firkins. 2009. Interaction of unsaturated fat or coconut oil with monensin in lactating dairy cows fed 12 times daily. I. Protozoal abundance, nutrient digestibility, and microbial protein flow to the omasum. J. Dairy Sci. 95 :2046-2060. 
Roche, J.R., N.C. Friggens, J.K. Kay, M.W. Fisher, K.J. Stafford, and D.P. Berry. 2009. Invited review: Body condition score and its association with dairy cow productivity, health, and welfare. J. Dairy Sci. 7:2395-2405.

Russell, J. B. 1987. A proposed mechanism of monensin action in inhibiting ruminant bacterial growth: Effects on ion flux and proton motive force. J. Anim. Sci. 64:15191525.

Russell, J. B., M. A. Cotta, and D. B. Dombrowski. 1981. Rumen bacterial competition in continuous culture: Streptococcus bovis versus Megasphaera elsdenii. Appl. Environ. Microbiol. 41:1394-1399.

Russell, J. B., and D. B. Dombrowski. 1980. Effect of pH on the efficiency of growth by pure cultures of rumen bacteria in continuous culture. Appl. Environ. Microbiol. 39:604610.

Russell, J. B., and T. Hino. 1985. Regulation of lactate production in Streptococcus bovis:A spiraling effect that contributes to rumen acidosis. J. Dairy Sci. 68:1712-1721.

Russell, J. B., and H. J. Strobel. 1988. Effects of additives on in vitro ruminal fermentation: A comparison of monensin and bacitracin, another gram-positive antibiotic. J. Anim. Sci. 66:552-558.

SAS Institute. 2004. SAS/STAT 9.3 User's Guide. SAS Inst. Inc., Cary, NC.

Sauer, F. D., J. K. G. Kramer, and W. J. Cantwell. 1989. Antiketogenic effects of monensin in early lactation. J. Dairy Sci. 72:436-442.

Schingoethe, D.J., K.N. Linke, K.F. Kalscheur, A.R. Hippen, D.R. Rennich, and I. Yoon. 2004. Feed efficiency of mid-lactation dairy cows fed yeast culture during summer.

J. Dairy Sci. 87:4178-4181.

Slyter, L. L. 1976. Influence of acidosis on rumen function. J. Anim. Sci. 43:910-929.

Sniffen, C. J., R. W. Beverly, C. S. Mooney, M. B. Roe, and A. L. Skidmore, and J. R. Black. 1993. Nutrient requirements versus supply in the dairy cow: strategies to account for variability. J. Dairy Sci. 76:3160-3178.

Stone, W. C. 2004. Nutritional approaches to minimize subacute ruminal acidosis and laminitis in dairy cattle. J. Dairy Sci. 87:(E. Suppl.):E13-E26.

Suthar, V. S., J. Canelas-Raposo, A. Deniz, and W. Heuwieser. 2013. Prevalence of subclinical ketosis and relationships with postpartum diseases in European dairy cows. J. Dairy Sci. 96:2925-2938. 
Tajima, K., S. Arai, K. Ogata, T. Nagamine, H. Matsui, M. Nakamura, R. I. Aminov, and Y. Benno. 2000. Rumen bacterial community transition during adaptation to high-grain diet. Anaerobe. 6:273-284.

Van Soest, P. J. (1994) Nutritional Ecology of the Ruminant, 2nd ed. Cornell University Press, Ithaca, NY. p 137, 242.

Van Soest, P. J., J. B. Robertson, and B. A. Lewis. 1991. Methods for dietary fiber, neutral detergent fiber, and nonstarch polysaccharides in relation to animal nutrition. $\mathrm{J}$. Dairy Sci. 74:3583-3597.

Wallace, R. J., N. McKain, K. J. Shingfield, and E. Devillard. 2007. Isomers of conjugated linoleic acids are synthesized via different mechanisms in ruminal digesta and bacteria. J. Lipid Res. 48:2247-2254.

Wang, J.P., D.P. Bu, J. Q. Wang, X.K. Huo, T.J. Guo, H.Y. Wei, L.Y. Zhou, R.R. Rastani, L.H. Baumgard, and F.D. Li. 2010. Effect of saturated fatty acid supplementation on production and metabolism indices in heat-stressed mid-lactation dairy cows. J. Dairy Sci. 93:4121-4127.

Wang, X., X. Li, C. Zhao, P. Hu, H. Chen, Z. Liu, G. Liu, and Z. Wang. 2012. Correlation between composition of the bacterial community and concentration of volatile fatty acids in the rumen during the transition period and ketosis in dairy cows. Appl. Environ. Microbiol. 78:2386-2392.

Warner, A. C. I. 1962. Some factors influencing the rumen microbial population. J. Gen. Microbiol. 28:129-146.

Weimer, P.J., D.M. Stevenson, and D.R. Mertens. 2010. Shifts in bacterial community composition in the rumen of lactating dairy cows under milk fat-depressing conditions. J. Dairy Sci. 93:265-278.

Williams, P.E., C.A. Tait, G.M. Innes, and C.J. Newbold. 1991. Effects of the inclusion of yeast culture (Saccharomyces cerevisiae plus growth medium) in the diet of dairy cows on milk yield and forage degradation and fermentation patterns in the rumen of steers. J. Anim. Sci. 69:3016-3026.

Yang, W. Z., and K. A. Beauchemin. 2006. Physically effective fiber: Method of determination and effects on chewing, ruminal acidosis, and digestion by dairy cows. J. Dairy Sci. 89:2618-2633.

Yoon, I.K., and M.D. Stern. 1995. Influence of direct-fed microbials on ruminal microbial fermentation and performance of ruminants: A review. Australas. J. Anim. Sci. 8:533-555. 
Yoshii, T., N. Asanuma, and T. Hino. 2003. Number of nitrate- and nitrite-reducing Selenomonas ruminantium in the rumen, and possible factors affecting its growth. Anim. Sci. J. 74:483-491.

Zebeli, Q., M. Tafaj, H. Steingass, B. Metzler, and W. Drochner. 2006. Effects of physically effective fiber on digestive processes and milk fat content in early lactating dairy cows fed total mixed rations. J. Dairy Sci. 89:651-668.

Zebeli, Q., S. J., Terrill, A. Mazzolari, S. M. Dunn, W. Z. Yang, and B. N. Ametaj. 2012. Intramruminal administration of Megasphaera elsdenii modulated rumen fermentation profile in mid-lactation dairy cows. J. Dairy Res. 79:16-25. 
APPENDIX A: TABLES 
Table 1. Ingredient composition of dry cow and lactating (high) cow diets (\% of DM)

\begin{tabular}{lcc}
\hline Item & Dry & High \\
\hline Wheat straw & 26.6 & 4.01 \\
Corn silage & 45.7 & 36.0 \\
Corn grain, ground & $\mathrm{NA}^{2}$ & 13.4 \\
Soybean meal and whey blend & $\mathrm{NA}$ & 8.76 \\
Soybean meal, 48\% CP & 11.2 & 4.46 \\
Soybean hulls & $\mathrm{NA}$ & 10.1 \\
Amino Plus & $\mathrm{NA}$ & 5.54 \\
Wet distillers grains, 35\% DM $_{\text {Wet brewers grains }}^{\mathrm{NA}}$ & 5.53 \\
Dry cow grain mix & 12.4 & 6.46 \\
High cow grain mix & 4.10 & $\mathrm{NA}$ \\
\hline
\end{tabular}

${ }^{\mathrm{T}}$ AMINOPLUS ${ }^{\circledR}, \mathrm{Ag}$ Processing Inc. ${ }^{\circledR}$, Omaha, NE

${ }^{2} \mathrm{NA}=$ Not applicable 
Table 2. Chemical composition of the diet formulated by the herd nutritionist and the chemical composition of the actual diet fed

\begin{tabular}{lcccc}
\hline & \multicolumn{2}{c}{ Formulated } & \multicolumn{2}{c}{ Actual } \\
\cline { 2 - 5 } Variable & Dry Cows & High Cows & Dry Cows & High Cows \\
\hline DM, \% & 45.6 & 48.5 & 42.4 & 47.5 \\
CP, \% of DM & 15.5 & 18.9 & 13.3 & 17.6 \\
NDF, \% of DM & 44.9 & 31.5 & 49.5 & 31.2 \\
NFC,$\%$ of DM & 28.1 & 40.0 & 26.6 & 40.8 \\
Starch, \% of DM & 16.2 & 26.2 & NA $^{2}$ & NA \\
Fat, \% of DM & 3.1 & 3.83 & 2.91 & 3.59 \\
Ash, \% of DM & NA & NA & 7.73 & 6.80 \\
K, \% & 1.22 & 1.51 & 1.06 & 1.20 \\
P, \% & 0.32 & 0.34 & 0.32 & 0.40 \\
Ca, \% & 1.27 & 0.75 & 1.01 & 0.79 \\
Mg, \% & 0.34 & 0.28 & 0.31 & 0.34 \\
S, \% & 0.26 & 0.22 & 0.22 & 0.24 \\
Cu, ppm & 29.9 & 20.1 & 33.1 & 21.8 \\
Fe, ppm & NA & NA & 309 & 295 \\
Mn, ppm & 141 & 85.1 & 113 & 74.2 \\
Mo, ppm & NA & NA & 2.90 & 2.33 \\
Zn, ppm & 122 & 80.2 & 123 & 93.4 \\
\hline
\end{tabular}

${ }^{1} \mathrm{NFC}=$ non-fiber carbohydrate $=100-(\% \mathrm{NDF}+\% \mathrm{CP}+\%$ fat $+\%$ ash $)$

${ }^{2} \mathrm{NA}=$ Not available 
Table 3. Least square means of body condition score, body weight, urine ketones, plasma NEFA and BHBA, milk production, and milk composition in cows not dosed and cows dosed with $M$. elsdenii $\sim 14 \mathrm{~d}$ prepartum, 1 to $3 \mathrm{~d}$ postpartum, or $\sim 14 \mathrm{~d}$ prepartum and 1 to $3 \mathrm{~d}$ postpartum

\begin{tabular}{|c|c|c|c|c|c|c|c|c|}
\hline \multirow[b]{2}{*}{ Item } & \multicolumn{4}{|c|}{ Treatment } & \multicolumn{4}{|c|}{$\mathrm{P}$-value } \\
\hline & Control & Prepartum Dose & Postpartum Dose & Pre \& Post Dose & SEM & TRT & Time $^{\dagger}$ & TRT x Time \\
\hline $\mathrm{BCS}^{1}$ & 3.01 & 3.05 & 2.99 & 2.92 & 0.05 & 0.28 & 0.01 & 0.83 \\
\hline $\mathrm{BW}^{1}, \mathrm{~kg}$ & $685^{\mathrm{a}}$ & $656^{\mathrm{b}}$ & $657^{\mathrm{ab}}$ & $690^{\mathrm{ac}}$ & 13.6 & 0.04 & $\mathrm{NA}^{1}$ & NA \\
\hline Milk, kg/d & 39.7 & 39.7 & 39.5 & 39.8 & 0.97 & 1.00 & 0.01 & 0.70 \\
\hline Projected 305d Milk, kg & 10,371 & 10,405 & 10,317 & 10,362 & 216 & 0.99 & 0.28 & 0.49 \\
\hline Peak milk, kg/d & 45.2 & 45.1 & 45.5 & 46.1 & 1.1 & 0.93 & NA & NA \\
\hline Peak milk, wk & 9.1 & 8.8 & 8.8 & 8.6 & 0.4 & 0.87 & NA & NA \\
\hline Fat, \% & 3.55 & 3.62 & 3.75 & 3.55 & 0.11 & 0.51 & 0.01 & 0.75 \\
\hline Protein, $\%$ & 3.07 & 3.04 & 3.09 & 3.07 & 0.04 & 0.86 & 0.01 & 0.68 \\
\hline $\mathrm{SCC}^{1}, 10^{3}$ cells $/ \mathrm{ml}$ & 277 & 349 & 381 & 326 & 96 & 0.88 & 0.31 & 0.05 \\
\hline Urine ketone, $\mathrm{m} \xi \mathrm{6} 65$ & 2.78 & 7.43 & 6.43 & 1.30 & 2.39 & 0.23 & NA & NA \\
\hline Prepartum NEFA ${ }^{1}, \mathrm{mEq} / \mathrm{L}$ & 0.28 & 0.30 & 0.26 & 0.25 & 0.03 & 0.74 & NA & NA \\
\hline Postpartum NEFA, mEq/L & 0.35 & 0.45 & 0.40 & 0.35 & 0.04 & 0.25 & NA & NA \\
\hline Prepartum BHBA ${ }^{1}, \mathrm{mg} / \mathrm{dl}$ & 11.6 & 10.8 & 9.76 & 10.2 & 0.80 & 0.38 & NA & NA \\
\hline Postpartum BHBA, mg/dl & 11.5 & 12.0 & 11.2 & 12.2 & 0.45 & 0.43 & NA & NA \\
\hline
\end{tabular}

${ }^{\mathrm{abc}}$ Means in the same row with different superscripts differ $(P<0.05)$.

${ }^{1} \mathrm{BCS}=$ Body condition score, $\mathrm{BW}=$ body weight, $\mathrm{SCC}=$ somatic cell count, $\mathrm{NEFA}=$ nonesterified fatty acids, $\mathrm{BHBA}=\beta$-hydroxybutyrate, and NA = not applicable

${ }^{\dagger}$ Time relates to the 0,30,60, and 90 DIM for BCS; week for milk yield; and DHI test day for 305 d predicted milk, milk fat, milk protein, and SCC 
Table 4. Incidence of health events within each treatment (\% of cows with health event) until 90 DIM and least square means for reproductive performance until 150 DIM for cows not dosed and cows dosed with M. elsdenii $\sim 14 \mathrm{~d}$ prepartum, 1 to $3 \mathrm{~d}$ postpartum, or $\sim 14 \mathrm{~d}$ prepartum and 1 to $3 \mathrm{~d}$ postpartum

\begin{tabular}{|c|c|c|c|c|c|c|}
\hline \multirow[b]{2}{*}{ Item } & \multicolumn{4}{|c|}{ Treatment } & \multicolumn{2}{|c|}{ P-value } \\
\hline & Control & Prepartum Dose & Postpartum Dose & Pre \& Post Dose & SEM & TRT \\
\hline \multicolumn{7}{|l|}{ Health Events } \\
\hline $\mathrm{RP}^{1}$ & 2.27 & 2.22 & 2.56 & 2.94 & 2.48 & 1.00 \\
\hline Milk fever & 2.27 & 2.22 & 2.56 & 0.0 & 2.15 & 0.85 \\
\hline Lame & 2.27 & 6.67 & 0.0 & 8.82 & 3.21 & 0.22 \\
\hline Hoof abscess & 0.0 & 0.0 & 2.57 & 5.89 & 2.12 & 0.19 \\
\hline Diarrhea & 0.0 & 2.22 & 0.0 & 0.0 & 1.24 & 0.46 \\
\hline Mastitis & 22.8 & 13.4 & 8.05 & 18.0 & 8.39 & 0.62 \\
\hline \multicolumn{7}{|l|}{ Reproduction } \\
\hline DIM at $1^{\text {st }}$ Service & 74.0 & 74.2 & 74.6 & 71.5 & 1.55 & 0.55 \\
\hline $\begin{array}{l}\text { Pregnant by } 150 \text { DIM, \% } \\
\text { cows }\end{array}$ & 68.2 & 66.7 & 76.9 & 61.8 & 7.38 & 0.57 \\
\hline Services/conception ${ }^{\dagger}$ & 1.53 & 1.57 & 1.77 & 1.71 & 0.15 & 0.61 \\
\hline
\end{tabular}

${ }^{\mathrm{T}} \mathrm{RP}=$ retained placenta and $\mathrm{HHW}=$ hairy heel wart

${ }^{\dagger}$ Services/conception= cows confirmed pregnant by 150 DIM 
APPENDIX B: FIGURES 


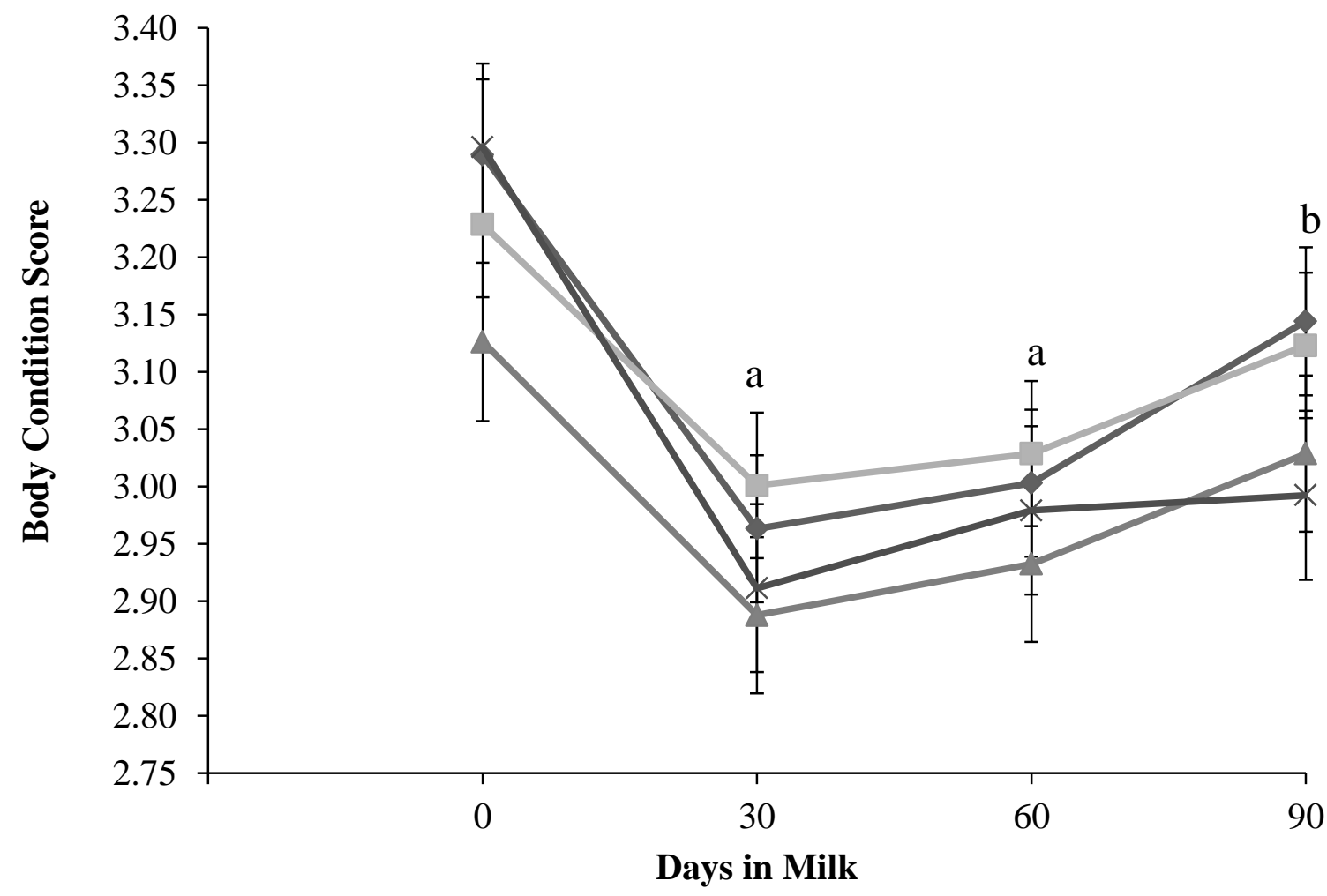

$\leadsto$ Control $\leftarrow$-Prepartum Dose $\leftarrow$ Postpartum Dose $*$ Pre- \& Postpartum Dose

${ }^{a b}$ Days in milk with different superscripts differ $(P<0.05)$.

Figure 1. Body condition score from 2 wk prepartum to 90 DIM for control, prepartum dosed, postpartum dosed, and pre- and postpartum dosed cows. 


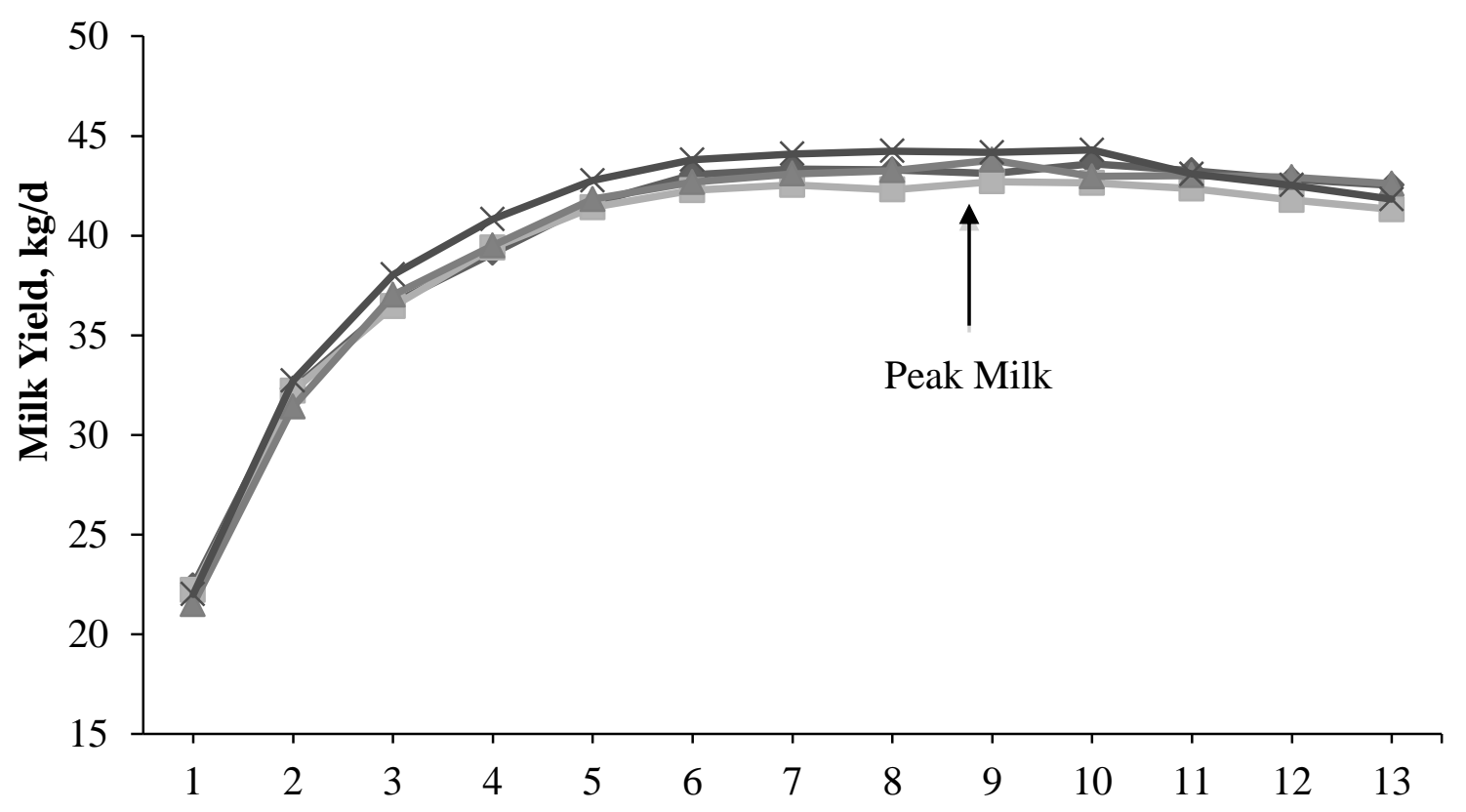

Week of Lactation

$\neg$ Control $\neg-$ Prepartum Dose $\leftarrow$ Postpartum Dose $\leftarrow$ Pre- \& Postpartum Dose

Figure 2. Milk production from wk 1 to 13 of lactation for control, prepartum dosed, postpartum dosed, and pre- and postpartum dosed cows. 


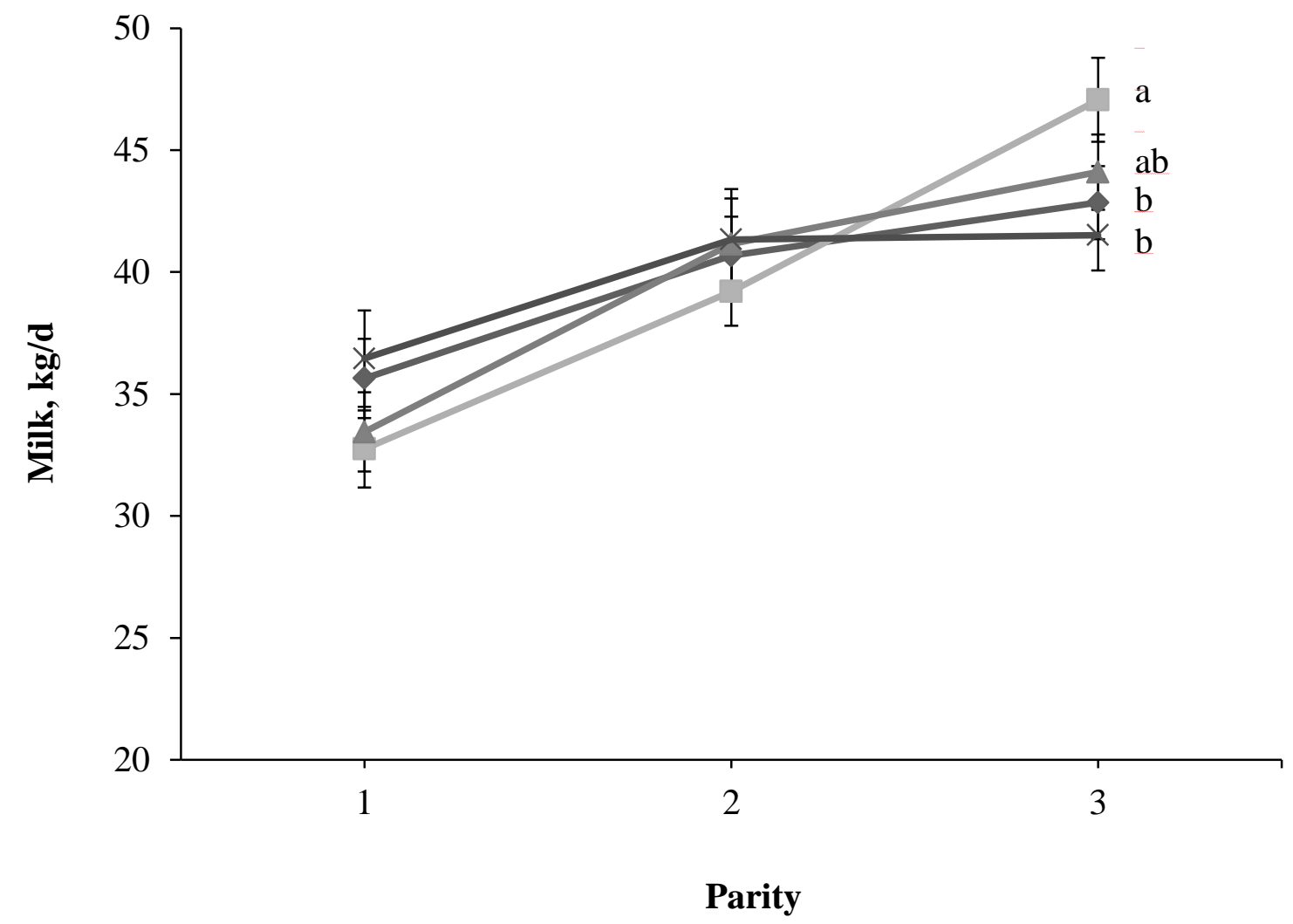

$\multimap$ Control - -Prepartum Dose $\leftarrow$ Postpartum Dose $*$ Pre- \& Postpartum Dose ${ }^{\mathrm{ab}}$ Treatments with different superscripts differ $(P<0.05)$.

Figure 3. Treatment by parity interaction $(P<0.05)$ for milk yield for control, prepartum dosed, postpartum dosed, and pre- and postpartum dosed cows. 


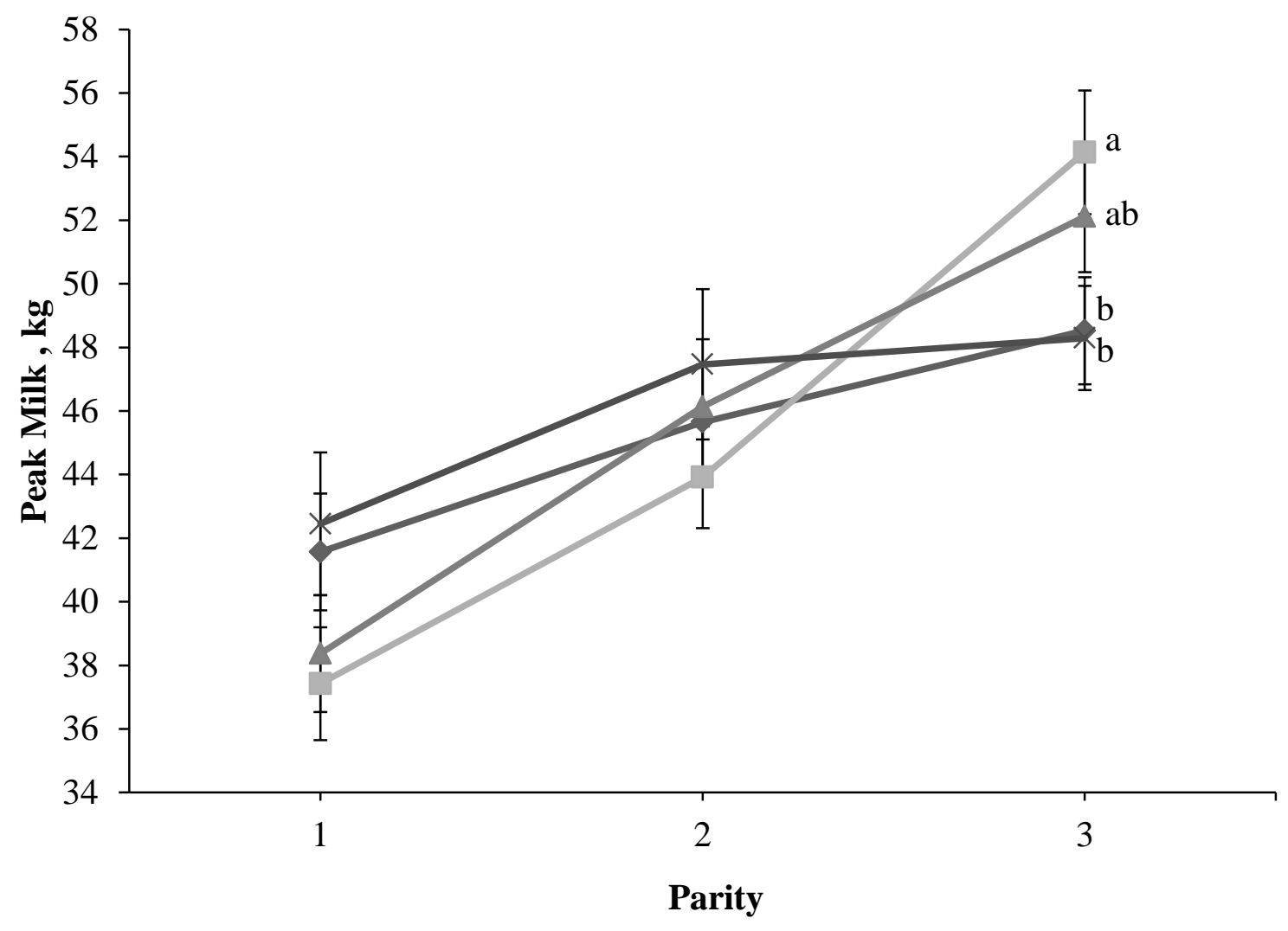

$\neg$ Control $\_-$Prepartum Dose $\leftarrow$ Postpartum Dose $*$ Pre- $\&$ Postpartum Dose

${ }^{\mathrm{ab}}$ Treatments with different superscripts differ $(P<0.05)$.

Figure 4. Treatment by parity interaction $(P<0.05)$ for peak milk for control, prepartum dosed, postpartum dosed, and pre- and postpartum dosed cows. 


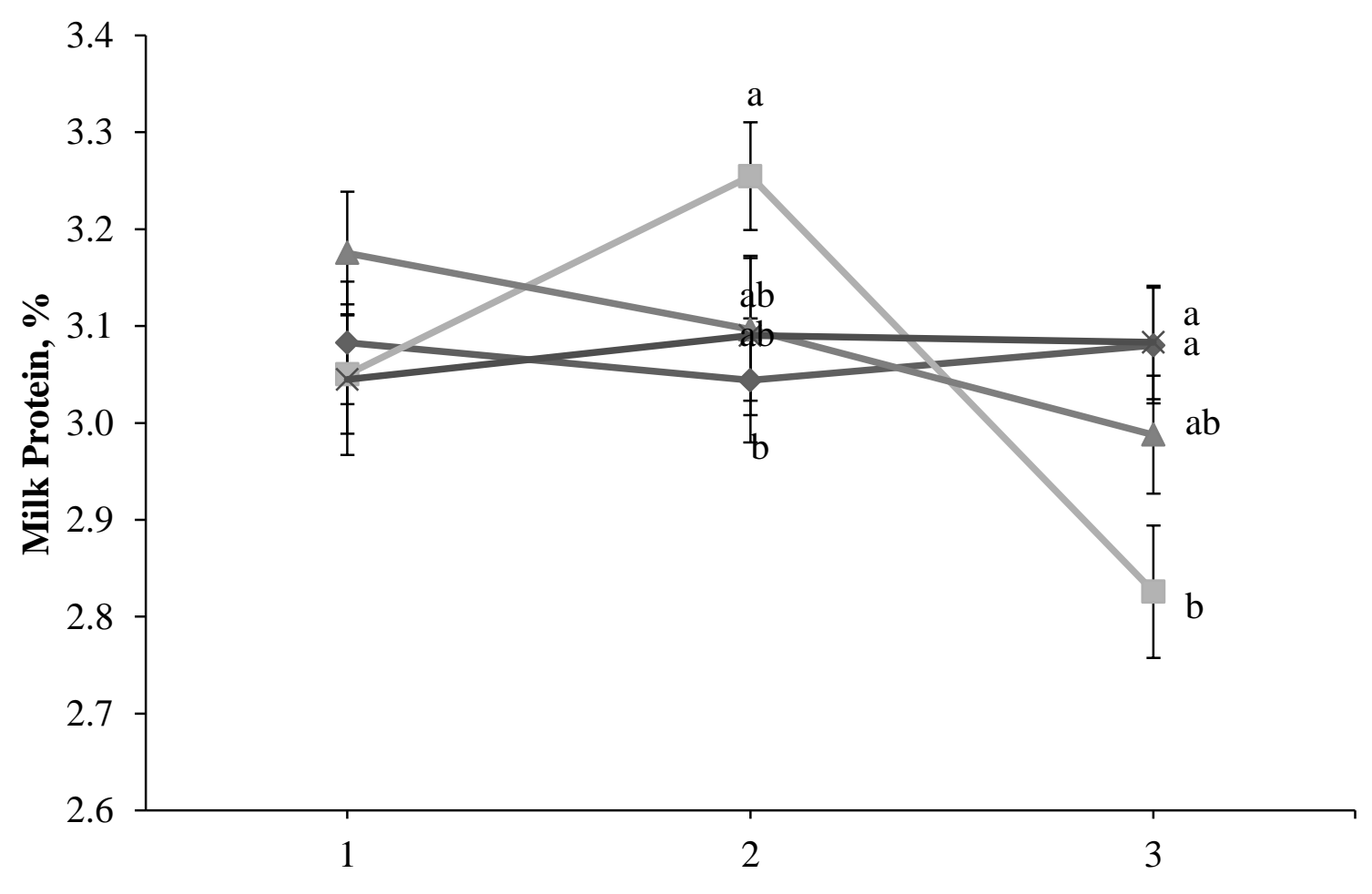

Parity

$\leadsto$ Control $\_-$Prepartum Dose $\triangle$-Postpartum Dose $*$ Pre- \& Postpartum Dose

${ }^{\mathrm{ab}}$ Treatments with different superscripts differ $(P<0.05)$.

Figure 5. Treatment by parity interaction $(P<0.05)$ for milk protein percentage for control, prepartum dosed, postpartum dosed, and pre- and postpartum dosed cows. 